\title{
Declining Discount Rates: Economic Justifications and Implications for Long-Run Policy
}

\author{
Christian Gollier, Phoebe Koundouri, Theologos Pantelidis \\ IDEI, Université Toulouse I; DIEES, Athens University of Economics and Business; DEFA, National University \\ of Ireland Maynooth
}

June 2008

\begin{abstract}
.
The use of a Declining Discount Rate (DDR), in cost-benefit analysis (CBA), compared to the use of a Constant Discount Rate, implies that the policy maker will put relatively more effort to improve social welfare in the far distant future than in the shorter time. The choice between the two discount rates is crucial and linked, for example, to the problem of whether we should fight malaria and AIDS (which have immediate effects) rather than climate change (which is expected to have important long-term effects). In this paper we assess the willingness to pay for (very) distant benefits, which should inform the desirability of policies and projects with immediate costs and distant benefits. DDRs offer an approach to balancing current costs and distant benefits. First we present the existing theoretical justifications for using a DDR, which are mainly driven by the uncertainty of future economic conditions, and show how a theory-consistent optimal trajectory of the
\end{abstract}


DDR can be estimated. For this empirical estimation, we use regime-switching models of the optimal trajectory of the DDR for nine 'representative' countries. We then compose a weighted average rate that can be used in CBA of long-term projects that affect the global environment and economy. Finally, we investigate the policy implications of applying this optimal trajectory on the cost-benefit evaluation of carbon mitigation policies and compare our results with those of the Stern Review. This comparison provides empirical evidence that support the major criticism of the Stern Review of assuring high damage numbers by using an arbitrary low and constant discount rate. Our main point in this paper is that when uncertainty is introduced, the case for DDRs and the availability of a reliable empirical method for their estimation become compelling for CBA of long-run policies and projects.

JEL Classification: C22; Q53.

Keywords: discount factor; discount rate; regime-switching model; climate change; Stern report.

Acknowledgements: We are grateful to three anonymous readers and the participants at the 47th Economic Policy Panel Meeting for their time and effort put into their constructive comments, which have resulted in useful improvements to our manuscript. We are also grateful to Simon Dietz, Cameron Hepburn and Chris Hope for providing us the time profile of global damages from the Stern Review model and for very useful discussions on the issue of the choice of the appropriate discount rate for climate change mitigation. We are also in debt to Giuseppe Bertola, Philippe Martin and Jan van Ours, for their guiding comments and suggestions on the proposal, first and final draft of this paper. 


\section{INTRODUCTION}

The realization that actions taken today can have long-term consequences, presents a new challenge to decision makers in assessing the desirability of policies and projects, a challenge summarized as the goal of 'sustainable development'. The use of the classical net present value (NPV) rule to assess the economic efficiency of policies with costs and benefits that accrue in the long-term is problematic. The welfare of future generations barely influences the outcome of such a rule when constant socially efficient discount rates are used for all time. The deleterious effects of exponential discounting ensure that projects that benefit generations in the far distant future at the cost of those in the present are less likely to be seen as efficient, even if the benefits are substantial in future value terms. From the perspective of social choice, the present yields a dictatorship over the future. This is illustrated in the conclusion of the Copenhagen Consensus in which different public investment projects have been examined by a panel of prestigious economists. Using standard cost-benefit analysis (CBA), they ranked projects with distant benefits (e.g. global warming) at the lowest level of priority compared to programs yielding almost immediate benefits (e.g. fighting malaria and AIDS, and providing sanitation in developing countries).

In this paper we attempt to assess the willingness to pay for distant benefits, which should inform the evaluation of (very) long-run policies and projects, in the presence of uncertainty about future economic conditions. This is a challenging task on the basis of existing evidence, not only because of market imperfections, but also because more in this than in other contexts, the future may be very different from the past. Recent economic literature on long-run CBA, proposes the use of a discount rate which declines with time, 
according to some predetermined trajectory. In comparison with the use of a constant discount rate, using a DDR raises the weight attached to the welfare of future generations. Indeed, DDRs offer a nice and nuanced approach to the balancing of current costs and (very) distant benefits. Following this literature, the key assumption of our framework of analysis is that of a declining, but time-stable structure of discount rates. This assumption allows us to connect the representative-individual intergenerational theory and the empirical treatment of country-specific historical data. To do this, we utilize a univariate model (which describes the uncertainty in the behavior of interest rates) and very long historical data (which captures centuries of historical events that affect the stochastic characteristics of the interest rate series) to describe the stochastic dynamics of the real interest rate and estimate a theory-consistent schedule of DDR for nine 'representative' countries. These country-specific DDR schedules are then used in a CBA of the global climate change mitigation policy.

In a nutshell, in this paper we answer the following questions. What formal justifications exist for using a DDR? If we accept the theoretical arguments for DDRs, how one can estimate the shape and behavior of these discount rates? And, what are the policy implications of applying the optimal trajectory of DDRs on the issue of whether emissions reduction should be given higher priority than other investments we make in our everyday life.

In section 2 we focus on the determination of efficient social discount rates and their term structure, given the impact of uncertainty about future economic conditions. Theory suggests that (in an uncertain economic environment) it is the persistency of the shocks on the growth rate of consumption (in the consumption-based approach) and of the 
shocks on short-term interest rates (in the production-based approach) which determines the shape of the term structure of the socially efficient discount rate. These two explanations are coherent with each other: persistent shocks on growth expectations translate into persistent shocks on interest rates, both yielding DDRs. Moreover, in the last part of section 2 we argue that equating non-constant discount rates with time-inconsistent behaviour is a fallacious interpretation of the literature. In section 3 we empirically estimate country-specific optimal time trajectories of the social discount rate, based on the theory of the production-based approach to DDRs. We first discuss the availability of appropriate data and the selection of appropriate econometric models for such an estimation. Our objective is to compose a weighted average rate that can be used in CBA of long-term projects that affect the global environment and economy. The use of this aggregate interest rate is based on the anticipation of a better international cooperation on the challenges raised by global changes to our planet.

One of the most important contributions of this paper is that it proposes how the optimal, theory-consistent, long-run trajectory of the decline in discount rates can be estimated, without the use of a structural model. It is true that the relevant literature contains numerous studies that define a structural model where the yield curve is determined by a number of factors, such as the growth rate of consumption, or the short-term interest rate. However, all structural models are based on specific assumptions and their behaviour is sensitive to these assumptions. Empirically, structural models often lead to "economic puzzles" since they fail to explain what is actually observed in the markets. Structural uncertainty about extreme bad events (such as world wars and geophysical catastrophes) changes dramatically the dynamics of a structural model. 
Moreover, the rareness of extreme bad events makes it difficult to estimate accurately their possibility of occurrence based on available historical data. In general, structural parameters are empirically difficult to estimate and as a result the behaviour of structural models depends critically upon the prior beliefs of the researcher.

An alternative way to describe the dynamics of interest rates is by means of a simple univariate time series model where the future properties of the interest rate are determined by its own past behaviour. The uncertainty surrounding the future path of the interest rate (captured by the uncertainty of the estimated parameters of the univariate time series model) leads to DDRs. We argue that the empirical simplicity and theory-consistency of this approach (i.e. utilization of a univariate model for the interest rate) makes it preferable to the alternative approach of utilizing a structural model for characterizing the dynamics of interest rates. We, therefore, choose to perform the empirical analysis of this study by means of univariate time series models.

In section 4 we use our estimates for policy simulation. In particular, we illustrate the implications of using the estimated trajectory of DDR in the cost-benefit evaluation of carbon mitigation policies and the conclusions of the Stern report. The Stern Review represents a radical departure from earlier estimates of the economic significance of climate change damages. The significance of climate change is seemingly increased by an order of magnitude. It is thus natural that it is being hotly debated. The most widely debated issue in economic circles following the Review was the choice of the discount rate. Stern has been criticized of assuring high damage numbers by using low discount rates. The main policy implication of our paper is that the utilization of an arbitrary low constant discount rate profile (like the one adopted by the Stern Review) generates substantially 
higher values for the social cost of carbon as well as the damages from climate change, when compared to the respective values generated by the utilization of our robustly estimated, optimal long-run trajectory of the decline in discount rates. These results indicate that a declining discount profile can correct the insufficient representation of future generations, but at the same time better maintain that current generations discount the future. This reveals the importance of having an empirically convenient and reliable, as well as theory-consistent, empirical method for estimating this trajectory. In our concluding section we argue that the resulting difference in the present value calculations is significant enough to call the attention of the policy maker. Moreover, our results have implications for cost-benefit analyses of long-run policies, in general, as well as the ranking of projects with immediate and distant benefits.

\section{DETERMINATION OF EFFICIENT SOCIAL DISCOUNT RATES: THE THEORETICAL FRAMEWORK}

This section outlines how standard economic theory can imply DDRs. In section 2.1 and 2.2 , we review the two standard approaches for the determination of the socially efficient discount rates and their term structure. We link the two approaches in section 2.3, whereas we discuss in section 2.4 the issue of time inconsistency that arises when DDRs are used. 


\subsection{The Consumption-based Term Structure of Discount Rate}

Consider a marginal investment project that reduces current consumption by $\varepsilon$ and raises consumption by $e^{r t} \varepsilon$ at date $\mathrm{t}$ with certainty. The return of this project is $r$. Its effect on intertemporal welfare is

$$
-u^{\prime}\left(c_{0}\right)+e^{r t} e^{-\rho t} E u^{\prime}\left(c_{t}\right)
$$

where $c_{t}$ is consumption at date $t, \rho$ is the rate of pure preference for the present, and $u$ is the increasing and concave utility function. This certain investment project is positive (negative) if its return $r$ is larger (smaller) than $\delta_{t}$ which is defined as

$$
e^{-\delta_{t} t}=e^{-\rho t} \frac{E u^{\prime}\left(c_{t}\right)}{u^{\prime}\left(c_{0}\right)}
$$

Thus, $\delta_{t}$ is the socially efficient discount rate associated to cash-flows at date $t$. If we assume a power utility function with $u^{\prime}(c)=c^{-\gamma}$, and if we suppose that $X_{t}=\ln c_{t}-\ln c_{0}$ is normally distributed, the above equation simplifies to

$$
\delta_{t}=\rho+\mu g_{t}-0.5 \mu(1+\mu) \frac{\operatorname{Var}\left(X_{t}\right)}{t}
$$

where $g_{t}=t^{-1} \ln \left(E c_{t} / c_{0}\right)$ is the expected annualized growth rate of consumption. Equation (1) is the Ramsey rule (Ramsey (1928)) extended to an uncertain growth of the economy. $\mu$ represents the representative agent's preferences for smoothing consumption that is growing over time at a rate $g$ and is known variously as the elasticity of inter-temporal substitution, the elasticity of marginal utility of income, and inequality aversion in that it measures the curvature of the utility function $u$. It is mathematically equivalent to the coefficient of relative risk aversion (CRRA), defined by $\mu=-c u^{\prime \prime}(c) / u^{\prime}(c)$. It measures the percentage reduction in marginal utility when consumption is increased by $1 \%$. 
The intuition of the Ramsey rule when $\operatorname{Var}\left(X_{t}\right)=0$, i.e., when there is no uncertainty, is simple. When the growth rate $g_{t}$ of consumption is large, the marginal utility of future consumption is small, and the willingness to invest for the future is limited. This justifies a large discount rate. Why would we sacrifice current consumption in favour of future generations which will be so much wealthier than us anyway? ${ }^{1}$ This would be socially efficient only if the return of the investment would be large enough to compensate for the increased intergenerational wealth inequality that it would generate. This wealth effect specified by $\mu g_{t}$ in the Ramsey equation, is proportional to the elasticity of marginal utility, i.e., to $\mu$. If we assume that $\rho=0^{2}$ and $\mu \in[1,2],{ }^{3}$ the socially efficient discount rate should lie between the growth rate of consumption and twice it.

It is of course very difficult to predict the distant future. When we introduce uncertain growth rates of consumption, the Ramsey rule must be extended to take into account a precautionary motive by subtracting the precautionary term $0.5 \mu(1+\mu) t^{-1} \operatorname{Var}\left(X_{t}\right)$ in the right-hand side of equation (1). As shown in Gollier (2002a,b) this effect comes from the convexity of marginal utility, which tends to raise the expected marginal utility of future consumption when it is uncertain. This precautionary saving motive reduces the socially efficient discount rate, and this effect is proportional to the index $1+\mu=-c u^{\prime \prime \prime}(c) / u^{\prime \prime}(c)$ of convexity of $u^{\prime}$. It is intuitive that a prudent agent is willing to

\footnotetext{
${ }^{1}$ At a $2 \%$ growth rate per year, consumption will be more than 50 times larger in 200 years than today.

${ }^{2}$ Pearce and Ulph (1999) summarize various estimates of the appropriate utility discount rate. They conclude that the component for impatience (the 'rate of pure time preference') lies between zero and 0.5 percent (best guess $0.3 \%$ ), although they note that there is no clear view about the exact value of the rate of pure time preference. At this point, it is fair to mention that philosophers and many economists (including Ramsey) have long argued that for social decisions, anything other than a zero rate of pure time preference is unethical. ${ }^{3}$ The classic source on the estimation of the elasticity of intertemporal substitution is Stern (1977). Recent reviews are Cowell \& Gardiner (1999), Pearce and Ulph (1999), and Evans and Sezer (2002).
} 
sacrifice a larger fraction of current wealth to improve a more uncertain future. This is done by reducing the discount rate.

It is often overlooked that the (extended) Ramsey rule (1) is a theory of the term structure of interest rate. The socially efficient discount rate $\delta_{t}$ is a function of the time horizon $t$ through the potential time-dependency of $g_{t}$ and $t^{-1} \operatorname{Var}\left(X_{t}\right)$. If the growth of the economy is expected to accelerate, i.e., if $g_{t}$ is increasing, then the term structure of discount rates should be increasing. But an accelerating or a decelerating growth is never certain. This is why all recent attempts to justify a decreasing time structure of discount rates relied on introducing uncertainty into the picture. Once the context shifts to one of uncertainty, the case for DDRs becomes compelling.

Let $x_{t}=\ln c_{t}-\ln c_{t-1}$ denote the growth of the log consumption between date $t-1$ and $t$. It implies that $X_{t}=\sum_{\tau=1}^{t} x_{\tau}$. If the growth process is stationary, i.e., if the $x_{1}, x_{2}, \ldots$ are i.i.d., both $g_{t}$ and $t^{-1} \operatorname{Var}\left(X_{t}\right)$ are independent of $t$, and the term structure of discount rates $\delta_{t}$ should be flat. Suppose alternatively that there is some form of persistence in shocks on consumption. Positive serial correlations in growth rates per period will make the annualized variance $\sigma_{t}^{2}$ increasing in $t$. According to the extended Ramsey rule above, this would imply DDR to be socially efficient. Intuitively, persistence will imply that the very distant future will be particularly uncertain, which reinforces the precautionary motive to reduce the discount rate for these long time horizons.

This argument is developed in more details in Weitzman (2007b) and Gollier (2007). The first writer builds a "statistical optimal growth model" by combining a neoclassical economic model of optimal growth under uncertainty with a fully integrated 
Bayesian statistical model of estimating, updating and predicting the outcome of this uncertainty. His model is able to produce persistent uncertainty in the interest rate and as a result DDRs. From a different point of view, mainly driven by the existing finance literature on the term structure of interest rates, Christian Gollier reaches similar conclusions with more flexible preference functionals and stochastic growth processes. He, specifically, finds that a positively correlated growth process leads to a decreasing yield curve in the case of a prudent representative agent due to increased uncertainty for the distant future.

\subsection{The Production-based Term Structure of Discount Rates}

In the previous section, it was assumed that the investment was financed though a reduction of current consumption. Suppose alternatively that it is financed through a reduction of other productive investments. By a standard arbitrage argument, the discount rate that should be used to evaluate the new investment project equals the rate of return of the marginal investment in the production sector, which is the equilibrium interest rate in the economy. Let $x_{\tau}$ denote the interest rate from $\tau-1$ to date $\tau$, which may be uncertain from date $t=0$. Then the net present value of an investment that $\operatorname{costs} \varepsilon$ today and yields a benefit $\varepsilon e^{\delta_{t} t}$ at date $t$ equals

$$
E N P V=E\left[-\varepsilon+\varepsilon e^{\delta_{t} t} e^{-\sum_{t=1}^{t} x_{\tau}}\right]
$$

Equalizing the expected net present value to zero characterizes the socially efficient discount rate, which must thus be such that 


$$
e^{-\delta_{t} t}=E\left[e^{-\sum_{\tau=1}^{t} x_{\tau}}\right]
$$

Suppose first that the short-term interest rate is stationary, i.e., that $x_{1}, x_{2}, \ldots$ are i.i.d.. This implies that

$$
\delta_{t}=-\ln E e^{-x_{1}}
$$

for all $t$. When shocks on interest rate are temporary, the term structure of socially efficient discount rates is flat. Suppose alternatively that short-term interest rates $x_{1}, x_{2}, \ldots$ are perfectly correlated. In that case, equation (2) can be rewritten as

$$
e^{-\delta_{t} t}=E\left[e^{-x_{1} t}\right]
$$

Following Weitzman (1999), it is easy to show that $\delta_{t}$ is decreasing with the time horizon $t$. Thus, persistence in shocks on interest rates plays a key role in DDRs.

Simple time series models can describe the uncertainty in the behavior of interest rates and it is uncertainty, together with persistence of the interest rates that leads to DDRs. This can be illustrated in the context of a simple autoregressive model of order one, i.e. AR(1). Specifically, assume the following AR(1) model for the interest rate, $x_{t}$ :

$$
x_{t}=c+e_{t}, \quad e_{t}=p e_{t-1}+h_{t}, \quad h_{t} \sim \operatorname{iidN}\left(0, \sigma_{h}^{2}\right)
$$

where the mean of the process, $\mathrm{c}$, is normally distributed with mean $\bar{c}$ and variance $\sigma_{c}^{2}$. The higher $\sigma_{c}^{2}$ is, the greater the uncertainty that surrounds the mean interest rate. On the other hand, the closer $p$ gets (in absolute value) to unity, the more persistent the interest rate is. Newel and Pizer (2003) prove that the forward discount rate at time $t$ in the future is:

$$
\bar{x}_{t}=\bar{c}-t \sigma_{c}^{2}-\sigma_{h}^{2} f(p, t)
$$


where $f(p, t)$ is an increasing function in $t$ and $p$. Thus, the forward discount rate decreases with uncertainty (measured by $\sigma_{c}^{2}$ and $\sigma_{h}^{2}$ ) and persistence (measured by p).

The AR(1) model described above is a discrete-time version of Vasicek's (1977) model since it is linear with regards to the mean and it assumes a constant variance for the process. Since Vasicek's seminal paper, numerous studies in the finance literature proposed alternative models for the term structure of the interest rates. For example, Cox et al. (1985) relaxed the constant variance assumption by allowing the variance process to be a linear function of the level of the interest rate, while a few years later Chan et al. (1992) defined the variance process as a power function of the level of the interest rate. On the other hand, Hamilton $(1988,1989)$ argued that models with time-varying parameters provide a better framework to describe interest rates compared to models with constant parameters and he suggested a regime switching model for the interest rates. Regime switching models are well suited to capture the non-linearities in interest rates and thus they became very popular in empirical studies (see, among others, Gray (1996), Ang and Bekaert (2002)).

\section{Box 1. Uncertainty and DDRs: An Example}

The following simple example illustrates how uncertainty about the future path of the discount rate increases the present value (PV) of a future cash-flow and leads to Declining Discount Rates (DDRs).

Assume that a project generates a cash-flow of $€ 1000$ after $t$ years. Under scenario A, there is no uncertainty about the level of the discount rate in the future, which we assume to be 4 percent. The second column of Table B1 reports the PV of $€ 1000$ for different time horizons. 
Under scenario B, there is a low level of uncertainty about the future discount rate. Specifically, the rate could be either 3 percent or 5 percent with equal probability. Note that the average expected rate is 4 percent $\left(=0.5 * 0.03+0.5^{*} 0.05\right)$. In this case, the expected PV of $€ 1000$ received after $t$ years is $0.5 * 1000 * \mathrm{e}^{-0.03 \mathrm{t}}+0.5 * 1000 * \mathrm{e}^{-0.05 t}$. The third column of Table B1 presents the PV of the cash-flow for different time horizons. It is obvious that the PVs are now higher compared to the PVs under scenario A as illustrated in the fifth column of Table B1. For example, if the cash-flow is generated after 200 years, the PV under the low-uncertainty scenario (i.e. scenario B) is about 3.7 times higher than that under the no uncertainty scenario (i.e. scenario A). Note that the difference between the PVs of the two scenarios increases with the time horizon. Finally, under scenario $\mathrm{C}$, there is a high level of uncertainty about the future rate. Specifically, the rate could be either 1 percent or 7 percent with equal probability (note that the average expected rate is once again 4 percent). In this case, the PV of the $€ 1000$, reported in the fourth column of Table B1 for different time horizons, is substantially higher compared to the PV under scenario A. The calculated differences between the PVs of scenario A and C, reported in the last column of Table B1, are now significantly higher compared to the differences between the PVs of scenario A and B. For example, when the time horizon is 200 years, the PV under the high-uncertainty scenario (i.e. scenario C) is more than 200 times higher than that under the no uncertainty scenario (i.e. scenario A). Once again, the difference between the PVs of the two scenarios increases with the time horizon.

In summary, this example illustrates that uncertainty about the future discount rates increases the expected PV of future payoffs. Moreover, the increase in the expected PV of future payoffs is higher for higher levels of uncertainty and it is also higher for payoffs in the distant future. This results in forward discount rates that decline over time (i.e. DDRs) as proved by 
Weitzman (1998). The DDRs for scenario B and C are shown in Figure B2. The discount rate of the high-uncertainty scenario declines with the time horizon much faster compared to the discount rate of the low-uncertainty scenario. However, in both cases the discount rate tends to the lower possible rate (that is 3 percent under scenario $\mathrm{B}$ and 1 percent under scenario $\mathrm{C}$ ).

Table B1: Present Value of a cash-flow of $€ 1000$ received after $t$ years

\begin{tabular}{llllll}
\hline \hline t & $\begin{array}{l}\text { Scenario A: } \\
\mathbf{4 \%}\end{array}$ & $\begin{array}{l}\text { Scenario B: } \\
\mathbf{3 \%} \text { or 5\% }\end{array}$ & $\begin{array}{l}\text { Scenario C: } \\
\mathbf{1 \%} \text { or 7\% }\end{array}$ & $\begin{array}{l}\text { Percentage } \\
\text { difference } \\
\text { between A,B }\end{array}$ & $\begin{array}{l}\text { Percentage } \\
\text { difference } \\
\text { between A,C }\end{array}$ \\
\hline 1 & 960.7894 & 960.8375 & 961.2218 & 0.005 & 0.045 \\
10 & 670.3200 & 673.6744 & 700.7114 & 0.500 & 4.534 \\
50 & 135.3353 & 152.6076 & 318.3640 & 12.763 & 135.241 \\
100 & 18.3156 & 28.2625 & 184.3957 & 54.308 & 906.766 \\
150 & 2.4788 & 5.8310 & 111.5788 & 135.241 & 4401.412 \\
200 & 0.3355 & 1.2621 & 67.6681 & 276.220 & 20071.564 \\
300 & 0.0061 & 0.0619 & 24.8935 & 906.766 & 405054.203 \\
400 & 0.0001 & 0.0031 & 9.1578 & 2630.823 & 8137639.571 \\
\hline \hline
\end{tabular}

Figure B2: The forward discount rates

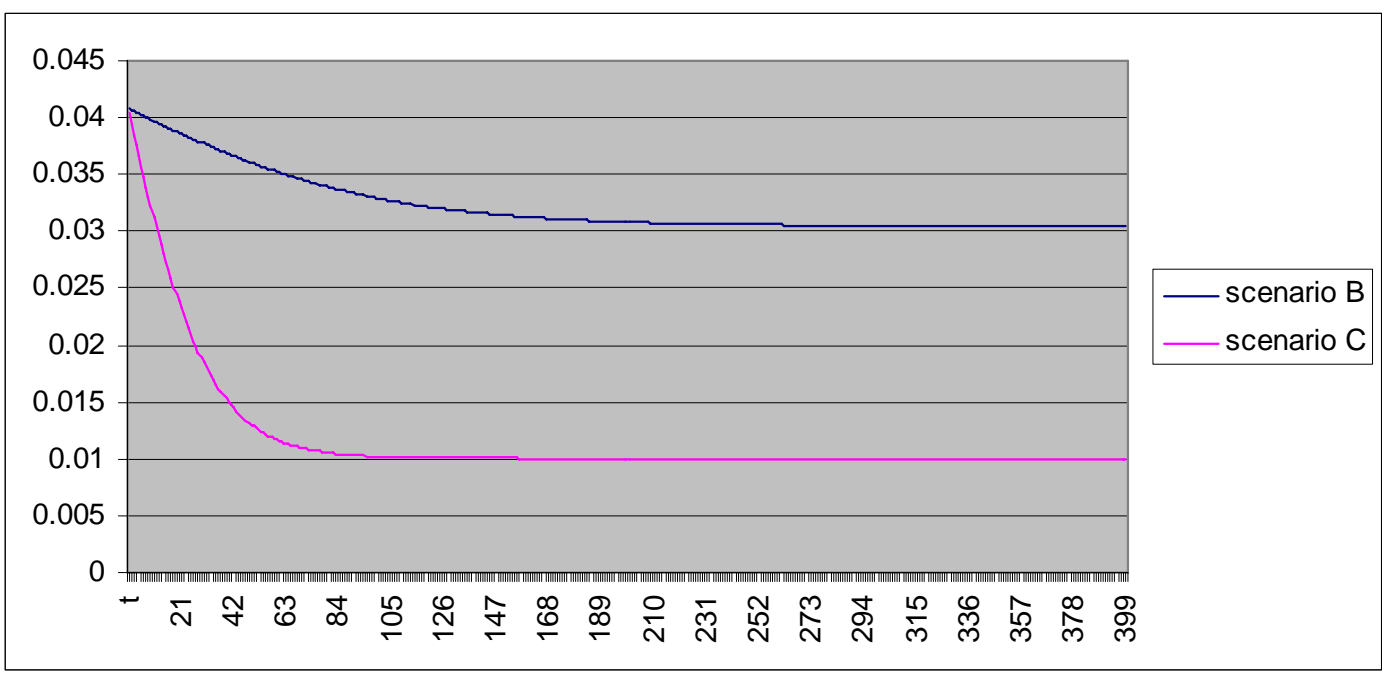




\subsection{Linking the Two Approaches of DDRs}

In a frictionless economy, it is irrelevant to know whether the new marginal investment project would be financed by a reduction in current consumption, or by a reallocation of capital, since the equilibrium interest rates equals the return on capital and the marginal rate of intertemporal substitution. Applying the extended Ramsey rule for a one-year horizon, we obtain that the equilibrium interest rate must equal

$$
\delta_{1}=\rho+\mu g_{1}-0.5 \mu(1+\mu) \sigma^{2},
$$

where $g_{1}$ is the expected growth rate and $\sigma^{2}$ is the variance of the growth rate of consumption. This means that there is a direct link between shocks on expectations about the growth of the economy, and shocks on the short-term interest rate.

We have made clear in the previous sections that it is the persistency of the shocks on the growth rate of consumption (in the consumption-based approach) and of the shocks on short-term interest rates (in the production-based approach) which determines the shape of the term structure of the socially efficient discount rate. The above equation shows that these two explanations are coherent with each others. Persistent shocks on growth expectations translate into persistent shocks on interest rates, both yielding DDRs.

In this paper, we use the production-based approach to DDRs. We have collected data to test for the persistence of shocks on interest rates, and we use equation (2) to characterize the term structure.

In reality, the two approaches are not perfectly equivalent in the real world. Distortionary income taxation alone will cause the return on capital to be larger than the marginal rate of intertemporal substitution. Imperfect competition, externalities in 
production and consumption, differences in the value of investment and consumption etc. will also cause a divergence. All of these factors require consideration in any given circumstance when conducting CBA. Much of the debate about discounting has concerned when and whether it is appropriate to use the consumption-based approach or the production-based approach, or some combination of the two. Furthermore, the specific Social Discount Rate (SDR) used for CBA will reflect the numeraire against which all costs and benefits are valued. Most commonly in CBA consumption is used as the numeraire, and thus $\delta$ is often referred to as the 'consumption rate of interest'. Changing the numeraire will change the level of the SDR, but will not change the outcome of the NPV rule.

\subsection{Time Inconsistency}

It has been clear since at least Strotz (1956) that the myopic use of non-constant discount rates results in time inconsistent plans. Dynamic inconsistency, or equivalently 'time inconsistency', arises when a plan determined to be optimal at a particular point in time is not optimal when considered at a later point in time. In this case, if the planner is unable to somehow commit future planners to the original plan, the plan will eventually be abandoned.

Equating non-constant discount rates with time-inconsistent behaviour is a fallacious interpretation of the literature. Let us make clear that an exponential discounting of future utility, which implies time-consistency, is compatible with a non-exponential discounting of future monetary flows, i.e., with a non-flat term structure of discount rates. To show this, consider the 3-period consumption-saving problem under certainty: 


$$
\begin{aligned}
& \max _{c_{0}, c_{1}, c_{2}} u\left(c_{0}\right)+e^{-\rho_{1}} u\left(c_{1}\right)+e^{-2 \rho_{2}} u\left(c_{2}\right) \\
& \text { s.t. } c_{0}+e^{-\delta_{1}} c_{1}+e^{-2 \delta_{2}} c_{2}=w,
\end{aligned}
$$

where $\rho_{t}$ is the per-period rate of impatience associated to time-horizon $t, \delta_{t}$ is the interest rate at date 0 of a zero-coupon bond with maturity at date $t$, and $w$ is the lifetime wealth of the agent. Exponential (utility) discounting holds only if $\rho_{1}=\rho_{2}$, and the term structure of (monetary) discount rates is flat if $\delta_{1}=\delta_{2}$. The first-order conditions are written as

$$
\lambda=u^{\prime}\left(c_{0}\right)=e^{\delta_{1}-\rho_{1}} u^{\prime}\left(c_{1}\right)=e^{2 \delta_{2}-2 \rho_{2}} u^{\prime}\left(c_{2}\right),
$$

which yields a single optimal consumption plan $\left(c_{0}^{*}, c_{1}^{*}, c_{2}^{*}\right)$ when combined with the budget constraint. Observe also that equations (3) are equivalent to the pricing formula obtained when using the consumption-based approach in the certainty context.

Let time pass, and consider the decision problem of the same agent at date $t=1$. Is the remaining consumption plan $\left(c_{1}^{*}, c_{2}^{*}\right)$ still optimal in the new context? The decision problem can now be written as

$$
\begin{aligned}
& \max _{c_{1}, c_{2}} u\left(c_{1}\right)+e^{-\rho_{1}} u\left(c_{2}\right) \\
& \text { s.t. } c_{1}+e^{-\hat{\delta}} c_{2}=e^{\delta_{1}}\left(w-c_{1}^{*}\right),
\end{aligned}
$$

where $\hat{\delta}$ is the short-term interest rate that prevails at date $t=1$. By a simple arbitrage argument, it can be checked that $\hat{\delta}=2 \delta_{2}-\delta_{1}$. The first-order conditions for this problem can be written as

$$
\hat{\lambda}=u^{\prime}\left(c_{1}\right)=e^{\hat{\delta}-\rho_{1}} u^{\prime}\left(c_{2}\right) .
$$

The two right equalities in (3) and (4) are compatible only if $\delta_{1}-\rho_{1}$ equals $2 \delta_{2}-2 \rho_{2}-\hat{\delta}+\rho_{1}$, which is true only if $\rho_{1}$ equals $\rho_{2}$, that is, only if utility discounting is exponential. Whether the term structure of (monetary) discount rates is flat, decreasing or 
increasing is irrelevant for the time consistency of individual and collective decisions. Agents are perfectly able to plan their future consumption levels with perfect foresight about the evolution of their expectations and of interest rates. On the contrary, the relative weight of utils at calendar date $t$ and $t+1$ must remain constant through time in order to get time consistent decisions.

A similar point can be made in an uncertain environment. In such an environment, the optimal consumption plan is state-dependent. It is time consistent if agents do not want to revise these state-contingent plans when time passes, and when uncertainty is progressively resolved. As in the certainty case, it requires exponential discounting, but it is fully compatible with a non-flat term structure.

\section{FROM THEORY TO PRACTICE: THE EMPIRICAL ESTIMATION OF THE OPTIMAL TRAJECTORY OF DDR}

The discussion in Section 2 brings to light some interesting issues concerning the characterization of the future path of interest rates. In the consumption-based approach, it is mainly persistence of shocks on consumption growth that leads to decline in discount rates over time. Similarly, persistence on shocks on interest rates is the force that generates DDRs in the production-based approach. However, the existence of persistence is an empirical question. This section shows how we can empirically estimate a schedule of DDRs based on available historical data. Our objective is to calculate a sequence of an aggregate DDR required for the case study examined in Section 4.

It should be clear by now that, in general, there are two different classes of models to describe the behavior of the term structure of the social discount rate. That is, structural 
models where forward rates are determined by exogenous variables (e.g. growth of consumption) and univariate time series models where forward rates are determined by past rates. The choice between the two approaches is not straightforward, since they both have advantages and disadvantages.

From a theoretical point of view, a structural model is able to represent the underlying economic relations and seems preferable to a simple univariate model. It is reasonable to believe that if the assumptions underlying a structural model are valid, it will produce better forecasts for the interest rate compared to a univariate model.

However, from an empirical point of view, the theoretical advantage of a structural model over a univariate one can turn into a disadvantage if any of the assumptions of the structural model is violated. On the other hand, the main assumption behind the univariate model is that past behaviour of interest rates can reveal useful information about the future dynamics of the series. Moreover, in the context of structural models, we need long-term forecasts of all the variables that determine the interest rates in order to calculate the projected values of the interest rates. This can create estimation problems due to the possible time-variation of the parameters of the model. Furthermore, the researcher is obliged to perform the analysis based on the period where data for all variables of the structural model are available. This can result in the loss of important information. On the other hand, a univariate model requires data only for the interest rate and thus the analysis is usually extended to longer periods. It is reasonable to expect that when the objective is to derive a schedule of discount rates for, say, the next 400 years, a model that is based on 150-200 years of data (i.e. information) will probably outperform a model that is based on, say, only 60-80 years of data. The data availability issue is very important in our case 
where we try to calculate an aggregate DDR based on a number of country-specific estimates.

In summary, we believe that structural models are well-suited for short-term forecasts. However, their empirical implementation to describe the behaviour of the term structure in the distant future creates a number of problems described above. Therefore, we choose to describe the behavior of interest rates in the context of univariate time-series models. The utilization of a univariate model allows us to extend the estimation sample using long historical data that cover more than 200 years in some cases. This allows us to capture many historical events that affect the stochastic characteristics of the interest rate series.

Our focus is on the determination of the stochastic nature of interest rates through the observed dynamics of the process. After a short description of the available dataset, we choose the optimal model to describe the real interest rate of the countries under scrutiny, that is, France, India, Japan and South Africa. We then generate a series of discount factors and DDRs for each country based on the simulation procedure introduced by Newel and Pizer (2003). In a similar manner, we also generate discount factors and DDRs for Australia, Canada, Germany, the UK and the US based on each country's optimal estimated model as suggested by Hepburn et al. (2008) for the first four countries and Groom et al. (2007) for the US. ${ }^{4}$ Afterwards, we construct the aggregate discount factor (and the

\footnotetext{
${ }^{4}$ In their simulation experiment, Hepburn et al. (2008) and Groom et al. (2007) set the initial value of the DDR equal to 3.5 and 4 percent, respectively. In this study, we set the initial value of the DDR equal to the sample mean. We therefore repeat the simulations for Australia, Canada, Germany, the UK and the US setting the initial value of the DDR equal to the sample mean in order to obtain a uniform set of results.
} 
corresponding aggregate DDR) as a weighted average rate of the nine discount factors of the individual countries.

\subsection{Data}

Social discount factors are prices of future consumption relative to consumption today. The relative price of future consumption could be calculated from the risk-free long-term interest rates. However, there are at least four arguments for the inappropriateness of simply using market prices: (a) market imperfections, (b) the super-responsibility of the government to both current and future generations, (c) the dual role of the members of the present generation in that in their political role they may be more concerned about future generations than their day-to-day activities on current markets would reveal, and (d) Sen's (1982) argument that individuals may be willing to join in a collective savings contract, even though they are unwilling to save as much in isolation. Although some of these positions generated heated argument, the overall view emerged that the real risk-free market interest rates provide an inappropriate conceptual basis for social discounting. However, the alternative of using the shadow price on capital in order to convert the magnitude of future effects to their consumption equivalents, is not currently used by policy makers, reflecting a mix of practicability and the view that the real risk-free interest rate and the shadow discount rate are quite close in magnitude (Spackman, 1991; Arrow, 1995; Pearce and Ulph, 1999). Based on these results, we use data on market interest rates for our empirical estimation.

We consider the real interest rate for France, India, Japan and South Africa. In an attempt to use the longest possible interest rate series, we choose the 10-year Government 
Bond Yield for France, the 7- and 20-year Government Bond Yields for Japan and South Africa respectively and the Government Bond Yield for India (as constructed by Global Financial Data). All interest rates are in domestic currency. Table 1 provided more information about the available sample and the series under scrutiny. We first calculate the real interest rate by subtracting the inflation rate (calculated based on the Consumer Price Index). Similarly to Newel and Pizer (2003), we assume that the inflation rate is zero before 1950. In order to preclude negative real interest rates from the analysis, we remove the effect of short periods of unusually high inflation (e.g. during the oil crisis in the mid '70s) using a simple dummy variable regression to subtract the extra level of inflation observed during that periods. This approach is followed for all countries except India. In the case of India, inflation is very high and volatile during the last 20 years, reaching 90 percent in some cases. Therefore, in the case of India and for the post-1973 period, we set the inflation rate equal to the average inflation rate during the pre-1973 period. In all cases, we consider a 4-year moving average real interest rate to smooth any short-term fluctuations. We then convert the real interest rate series to their continuously compounded equivalents. Finally, the estimation is based on the natural logarithm of the series to ensure that the simulated DDRs are positive. We should note that negative discount rates are unusual but not inconceivable. We choose to preclude negative discount rates for two reasons. First, we want to be consistent with previous studies, such as Groom et al. (2007), since we use some of their estimation results in our analysis. Second, we believe that negative rates are unlikely to persist for long periods. 
The basic descriptive statistics of the transformed series used in the estimation procedure are reported in Table 2. The French rate has the higher mean, while the Japanese rate is the more volatile one.

Table 1 here

Table 2 here

\subsection{Country-specific DDRs}

The aim of this section is to describe the statistical properties of the time path of the interest rates. There are numerous studies in the literature which argue that interest rates are subject to infrequent but important changes in the mean and the variance. The sources of these structural changes are not clear but are probably related to either monetary or fiscal policy. Moreover, the poor performance of various models (such as the Cox et al. (1985) model) in empirical studies to describe the yield curve may be attributed to the fact that they do not account for structural changes in the behavior of the interest rate. It is therefore important to choose a model for the interest rate that takes into account the existence of such structural changes, which is an important characteristic of the series. As a result, many researchers have chosen regime-switching models to describe either a single time series of an interest rate (e.g. Hamilton 1988 and Gray 1996) or the entire term structure of interest rates (e.g. Bansal and Zhou, 2001). We follow a similar procedure and choose a two-regime model to describe each interest rate series. Each one of the two regimes has a different mean as well as a different variance. The level of persistence of the process under each regime is also different. Finally, our specification allows for different lag order specification between regimes and countries. In summary, our parameterization describes a 
process that incurs a number of regime shifts over time where each regime has a different mean, variance and persistence. We can also estimate the average time that the process spends in each regime, which also determines the frequency of regime switches. Although we are not certain about the regime of the process in each point in time, we can easily estimate the probability of being in each regime over the sample period. The estimation results and the model selection procedure are described in more detail in Appendix A.

We then implement a simulation methodology to generate a series of discount factors (and the corresponding discount rates) for each country under examination. The simulation uses each estimated model to simulate 200.000 possible future paths of the interest rate. The simulation is structured so that it takes into account two different sources of uncertainty that characterize the estimated model. First, the simulation considers the typical uncertainty found in all stochastic models stemming from the stochastic nature of the error term. In other words, random draws of the error terms are generated for each simulated path. Second, the simulation accounts for the uncertainty that surrounds the point estimates of the parameters of the regime-switching model. Specifically, each simulated path of the discount rate uses a random draw for all the parameters of the model based on the point estimates and the estimated variance-covariance matrix of the parameters. The utilization of a two-regime model instead of a single-regime one allows for the possibility of regime switches in the future. In other words, irrespectively of the regime of the process during the recent years, the Regime-Switching (RS) model (and the simulation exercise) considers the possibility that the process incurs a number of regime changes in the future. This is crucial since we know that the calculated DDR depends on the level of uncertainty and thus the estimated model used in the simulation should be able 
to provide a relative good approximation of the actual uncertainty that surrounds the behavior of the discount rates. For each simulated series, we set the initial values equal to the sample mean of the real interest rate. ${ }^{5}$ One can reasonably argue that the long-period average is not an appropriate initial value for the simulation exercise, since it generates an initial value of the real interest rates that is higher than the real interest rates observed during the recent years in some developed countries. In order to examine the sensitivity of our results to the choice of the initial value in the simulations, at a later stage of our analysis we repeat the simulations setting the initial rate equal to 3.5 percent (that is, the rate currently used by HM Treasury for the evaluation of long-term projects). For the moment, we focus on estimated discount factors for the case where the initial values equal the sample mean of the series under examination.

The estimated discount factors and discount rates are reported in the first part of Tables 3 and 4, respectively. In general, we observe significant differences in the discount rates. France seems to produce the sharpest declining rate. Although the French one-period ahead rate is substantially higher than that of the other three countries, its terminal value (1.064 percent) is close to that of the Indian rate $(0.858$ percent $)$ and lower than the terminal rates of Japan and South Africa (1.39 and 2.358 percent respectively). On the other hand, the interest rate of South Africa declines very slowly, by only 1.5 percent in 400 years. The differences between the speed of decline in the country-specific discount rates mainly stems from the level of persistence of the individual series. The theoretical results presented in Section 2 show that (in an uncertain environment) it is persistence that leads to DDRs. The level of persistence determines the speed of decline in the forward

\footnotetext{
${ }^{5}$ See Groom et al. (2007) for further details about the design of the simulations.
} 
discount rates. In our case, the French interest rate is the more persistent one and thus it produces the sharpest DDR. On the other hand, the South-African interest rate is much less persistent than the other three rates under scrutiny, resulting in a slowly declining forward discount rate.

Table 3 here

Table 4 here

Tables 3 and 4 also report the estimated discount factors and rates for Australia, Canada, Germany, the UK and the US based on each country's estimated model as suggested by Hepburn et al. (2008) for the first four countries and Groom et al. (2007) for the US. We repeated the simulations of the two aforementioned studies by using a different initial value for the simulations. Specifically, we set the initial value equal to the sample mean. By doing so, we end up with a uniform set of nine DDRs. ${ }^{6}$

\subsection{Aggregation of the Discount Factors}

Environmental degradation is one of the most important issues that affect the globe. Growing international environmental interdependence and increased environmental awareness over the past years led to multilateral efforts to promote international policies and projects to mitigate problems like global warming and air pollution. The evaluation of such multinational projects requires the calculation of a proper "global" discount rate. We now try to compose such a discount rate. Specifically, we use the nine discount factor series calculated above to construct a weighted average discount factor profile (and the corresponding DDR profile) that can be used in cost-benefit analysis of long-term projects

\footnotetext{
${ }^{6}$ We should note that contrary to our sample that extends up to 2006, the estimation sample used by Hepburn et al. (2008) for Australia, Canada, Germany and the UK ends in 2004. Moreover, the estimation sample of
} 
that affect the global environment and economy. On the other hand, when evaluating projects that affect a single country, the cost-benefit analysis should be based on the country-specific discount factors (like the ones reported in Table 3 of our study). We believe that the aggregate discount factor profile is useful (and probably better than the discount factors of any individual country) when evaluating projects that have a global effect (e.g. climate change). The use of this aggregate interest rate is based on the anticipation of a better international cooperation to harmonise policies relating to the challenges raised by global changes to our planet. ${ }^{7}$

We consider three alternative weighting schemes in aggregating the country-specific discount factors. The first weighting scheme is based on the GDP of each country measured in Purchasing Power Parity terms. Specifically, the weight for each country equals the ratio of its GDP over the sum of the GDP of all nine countries under consideration. The second weighting scheme is based on annual $\mathrm{CO}_{2}$ emissions, that is, the weight of each country equals the ratio of its annual $\mathrm{CO}_{2}$ emissions over the total annual $\mathrm{CO}_{2}$ emissions of all nine countries of our sample. The third weighting scheme is based on the population size of each country in 2005 , that is, each country's weight equals the ratio of its population over the total population of all nine countries under examination. Obviously, the first weighting scheme is more meaningful than the other two from an economic point of view. On the other hand, we consider the three weighting scheme to be meaningful in environmental terms and thus our analysis is based on all three alternative weights for comparison reasons. Interestingly, the GDP and $\mathrm{CO}_{2}$ weights are similar

\footnotetext{
Groom et al. (2007) for the US ends in 1999.

${ }^{7}$ We calculate the aggregate DDR based on a sample of only nine countries. Obviously, we would have been able to estimate a "better" DDR (i.e. more representative of the global DDR) if additional large countries (e.g.
} 
resulting in similar aggregate discount factors and aggregate DDRs. Therefore, for brevity, the rest of the discussion is limited to the discount factors and DDRs calculated based on either the GDP or population weighting schemes. ${ }^{8}$ The two alternative weighting schemes are reported in Table 5. We should also note that the nine countries under examination correspond to about 46.8 percent of the world's GDP and about 28.34 percent of the world's population.

Table 5 here

The weighted average DDRs for the two alternative weighting schemes, presented in Table 6, have some differences but are in general close to each other. In general, the population-based aggregate rate is higher than the GDP-based aggregate rate for the first 300 years, becoming lower than the GDP-based aggregate rate for the last 100 years of the simulation. As a result, the terminal rate of the population-based aggregate rate is about 1.1 percent, that is, approximately 0.28 percent lower than that of the terminal GDP-based aggregate rate (which is about 1.38 percent).

Table 6 here

The results presented in Section 4 show that the two alternative weighting schemes generate quite similar valuations of climate change damages. In any case, we consider the GDP-based aggregate rate more reliable than the population-based aggregate rates for at least three reasons. First, GDP weights make more sense from an economic point of view. This is why the majority of empirical studies that compose an aggregate interest rate use weights based on GDP and the European Central Bank (ECB) calculates aggregate

Brazil, China and the Russian Federation) had been included in the analysis. Unfortunately, there are no reliable long historical data of interest rates series available for any of these countries. 
measures for the EU based on each member's GDP weight. Second, the nine countries under scrutiny account for about 46.8 percent of the world's GDP and about 28.34 percent of the world's population. Thus, the GDP-based aggregate rate seems to be more representative of the global DDR than the population-based aggregate rate. ${ }^{9}$ Third, in the context of our study, the behaviour of the population-based aggregate rate is mostly defined by the dynamics of the Indian rate, since the population-based weight for India is above 60 percent.

\section{DISCOUNTING CLIMATE CHANGE DAMAGES}

There are many uncertainties when it comes to the climate. There are uncertainties related to cloud formation, feedback from methane in melting permafrost and ecosystem responses to rapid change, to mention just a few. Hence it may come as a surprise to some non-economists that the main source of uncertainty in estimates of the economic consequences of climate change is something else: the discount rate. In fact, much of the critique of the Stern Review has focused not on the climate science embodied in the report or its assessment of the costs and benefits of climate change mitigation, but on the low discount rate used in the analysis and how this drives the central results of the Review (see e.g., Dasgupta (2006), Yohe (2006), Nordhaus (2007), Weitzman (2007a)). In this section, we investigate the policy implications of applying the two weighted average discount factors (and the corresponding DDRs) calculated in the previous section, on the

\footnotetext{
${ }^{8} \mathrm{We}$ also used an alternative weighting scheme, which is based on the projected population of each country in 2050. As expected, the results of this weighting scheme were similar to those based on each country's population in 2005 and are not reported for brevity.

${ }^{9}$ The fact that the aggregate DDR calculated based on the $\mathrm{CO}_{2}$-emissions weights (not reported for brevity) produces similar results to the GDP-based DDR reinforces our belief that the GDP-based DDR seems to be a better approximation to the "global DDR".
} 
cost-benefit evaluation of the carbon mitigation policies and the conclusions of the Stern report.

\subsection{The Discount Rate in the Stern Review}

The Stern Review contains a very careful and nuanced discussion of the discount issue (Stern, 2006, chapter 2). Under the assumption of a Constant Elasticity of Substitution (CES) utility function for consumption, the choice of the discount rate in the Review is based on the Ramsey equation $(\delta=\rho+\mu g)$ where $\delta$ is the discount rate, $\mu$ is the elasticity of the marginal utility of consumption, $g$ is the growth rate of consumption (which is time varying) and $\rho$ is the pure time discount rate or the rate of time preference. Since the growth rate is eventually depressed by climate change, the consumption discount rate falls through time. Moreover, because a small number of Monte Carlo draws simulate severe damages and therefore low growth, the certainty-equivalent falls towards the trajectory of the lowest rate (highest damages). This should be analogous to what happens in a schedule of time-declining discount rates based on past, exogenous volatility in growth.

However, the Review assumes that the elasticity of marginal utility is $\mu=1$, implying that the utility function is logarithmic. To accommodate for the fact that future generations will be richer, the growth effect to the discount rate is accounted for by assuming that the average annual rate of growth of consumption is $1.3 \%$ (Review, Box 6.3). Moreover, the Review argues that on ethical grounds the welfare of future generations should be treated at par with the welfare of the present generation, a position that implies the selection of a zero pure time discount rate. However, the Review also claims that 
uncertainty for the existence of the human race suggests that a positive rate should be selected instead (Review, Technical Annex to Postscript). Thus, the pure time discount rate is set at $0.1 \%$, meaning that the survival probability of the human race for 100 years is 0.91 . The Review acknowledges that there exist justifications for using higher pure time discount rates that suggest that pure time discount rate can be thought of as covering the possibility of reversing a particular investment. However these justifications are invalid in the case of climate change cost evaluation since "climate change is long-term, severe and irreversible". This is the reason why the justification that technological or other advances may mitigate climate change in the future, is not employed. In addition, it is supposed that future generations would willingly exchange conventional capital stock with improved environmental conditions in the future. As a result, the overall discount rate that is derived from the average growth of $1.3 \%$ is $1.4 \%$, which is an unusually low value!

This low discount rate is entirely consistent with the Ramsey rule, but it crucially depends on the chosen values for the structural parameters. If a researcher chooses a different value for any of these parameters, the calculated discount rate will be substantially different than 1.4 percent and as a result the CBA will probably lead to different conclusions. For example, with $\mu=2$, the socially efficient discount rate would be 2.7 percent. The discounting approach used in the Review and the chosen values for the structural parameters has been the subject of much controversy and criticism (see, for example, Dasgupta, 2006; Nordhaus, 2007). 


\subsection{The Social Cost of Carbon}

The social cost of carbon (SCC) is the shadow price of anthropogenic carbon dioxide emissions. The SCC is defined as the present value of the stream of damages from one ton of carbon. In this section the results of the two weighted average DDRs calculated in the previous section are applied to the calculation of the SCC. The SCC for each of the weighted discounting profiles is calculated based on the baseline damages scenario of the FUND 2.8 integrated assessment model, which reports the projected cost of emissions in \$ per ton of carbon emissions (Tol 2002a, 2002b). This model estimates the impacts of climate change to a wide variety of market and non market sectors like agriculture, forestry, sea-level rise, ecosystems, fatal vector-borne diseases, and fatal cardiovascular and respiratory disorders. The results represent the aggregation of the effects of climate change in 9 different regions: OECD-America (excl. Mexico), OECD-Europe, OECD-Pacific (excl. South Korea), Central and Eastern Europe and the former Soviet Union, Middle East, Latin America, South and Southeast Asia, Centrally Planned Asia, and Africa. The parameters used in the analysis are derived from the relevant literature. The results indicate that climate change will have different implications according to the region and the sector examined.

In Panel A of Table 7 we present the implied SCC using the GDP and 2005 population weighted profiles. In addition to the SCC calculated based on the estimated average discount factors (second column of Table 7 labeled "Average"), we also report lower and upper bounds for the SCC. More in detail, the lower bound corresponds to the SCC calculated based on the lower 2.5 percent quantile of the simulated distribution of the discount factors, while the upper bound corresponds to the SCC calculated based on the 
upper 97.5 percent quantile of the simulated distribution of the discount factors. ${ }^{10}$ Table 7 also reports the social cost of carbon under a constant discounting regime of $1.4 \%$ per year approximating the one implemented in the Stern Review. As a measure of comparison, the US Environmental Protection Agency estimates that the average 2-person household in the US produces approximately 20 tons of $\mathrm{CO}_{2}$ annually. ${ }^{11}$

Table 7 here

The social cost of carbon under GDP weighting is $12.60 \$ /$ tonC. When using population weighting, the overall social cost of carbon decreases by $29.76 \%$ to $8.85 \$ /$ tonC. Under the constant $1.4 \%$ rate, the social cost of carbon is $40.15 \$ /$ tonC. These results are indicative of the significance of discounting assumptions to the long-term valuation of climate change. Using a low albeit constant discount rate (1.4\%) increases the valuation of social benefits from $\mathrm{CO}_{2}$ abatement from 3.18 to 4.5 times than under declining discounting patterns. We now turn to the estimated 95 percent confidence intervals for the SCC that reveal the uncertainty that surrounds the calculated SCC. Specifically, under a scenario of high discount rates, the calculated SCC is as low as $3.09 \$ /$ tonC and $2.48 \$ /$ tonC for the GDP weighted and population weighted discount factors respectively. On the other hand, under a low discount rate scenario, the SCC increases to $23.69 \$ /$ tonC and $17.99 \$ /$ tonC for the GDP weighted and population weighted discount factors respectively. We should note however that in all cases the calculated SCC under the DDRs is substantially lower than that under the 1.4 percent constant discount rate.

As mentioned earlier in this study, it is interesting to examine the sensitivity of our results to the choice of the initial value in the simulation exercise that estimates the

\footnotetext{
${ }^{10}$ Due to computational limitations, we use 50.000 replications to obtain the upper and lower bounds.

${ }^{11} \mathrm{http}: / /$ www.epa.gov/climatechange/emissions/ind_calculator.html.
} 
discount factors and rates. Therefore, we repeat the simulations setting the initial rate equal to 3.5 percent. $^{12}$ Panel B of Table 7, reports the SCC estimated from GDP and Population weighted discount profiles given a 3.5 percent initial rate. The implied results are slightly higher compared to the original weighted discount schemes but still substantially lower compared to the constant $1.4 \%$ rate. We, thus, observe that setting a different initial value in the simulation exercise results in similar estimated SCC.

Figure 1 illustrates the evolution of benefits from a reduction of one ton in $\mathrm{CO}_{2}$ emissions over time for the GDP, population, GDP and Population with a 3.5\% initial value weighted schemes as well as for the $1.4 \%$ constant discount rates.

\section{Figure 1 here}

Figure 1 reveals that the majority of the benefits from reducing emissions by one ton of $\mathrm{CO}_{2}$ under both weighting schemes are accumulated until the year 2200. Between the year 2200 and 2400 the discounted benefits are of substantially smaller magnitude. Benefits under the two weighting profiles are consistently lower when compared to the constant $1.4 \%$ discounting profile. The benefits under GDP weighting are higher compared to the population weighting for the first 300 years, while this is reversed for the final 100 years. The utilization of a lower initial value of 3.5 percent has a minor effect on the evolution of benefits. The oscillating pattern in the lines of Figure 1 is caused by the nature of the damages assumed by the FUND 2.8 model. Specifically, damages from one ton of $\mathrm{CO}_{2}$ are assumed to remain constant across decades while the discounting profile is a yearly time series. Furthermore, the cost of carbon is greater in the short- and medium-term, but fall as carbon becomes sequestrated in the medium-term, thus generating the hump

\footnotetext{
${ }^{12}$ We should note that in cases where the mean value of the series (as suggested by the estimated model) is higher than 3.5 percent, setting the initial value to 3.5 percent results in a forward discount rate that initially
} 
shape. In Table 8 we display the present value of the benefits from reducing emissions by one ton at selected years while in Table 9 we report the marginal contribution to the present value at these years. Both tables illustrate that the contribution to aggregate benefits significantly flattens out after 150 years for both declining discount rate weights. On the other hand, benefits from abatement under constant $1.4 \%$ discounting exhibit similar noticeable flattening only after the $250^{\text {th }}$ year.

Table 8 here

Table 9 here

In Table 10 we report the estimated average social cost of carbon and its 95 percent confidence interval for each one of the nine countries under consideration. North American countries exhibit the highest SCC, since for the US and Canada the estimated values are $18.39 \$ /$ tonC $(3.90 \$ /$ tonC, $31.55 \$ /$ tonC $)$ and $11.65 \$ /$ tonC $(1.08 \$ /$ tonC, $30.23 \$ /$ tonC $)$ respectively. Australia has the next highest average SCC with $11.45 \$ /$ tonC (4.92\$/tonC, $20.96 \$$ tonC). The two major European industrial countries represented in the sample the UK and Germany cluster next with $9.40 \$ /$ tonC $(4.43 \$ /$ tonC, $16.54 \$ /$ tonC $)$ and $8.67 \$ /$ tonC (1.88\$/tonC, $19.89 \$ /$ tonC) respectively. For Japan the SCC is $8.45 \$ /$ tonC $(2.69 \$ /$ tonC, $17.39 \$ /$ tonC) and for South Africa with $7.95 \$ /$ tonC $(3.07 \$ /$ tonC, $16.05 \$ /$ tonC). France and India display roughly average identical SCC with $6.35 \$ /$ tonC $(1.35 \$ /$ tonC, $16.18 \$ /$ tonC) and $6.46 \$ /$ tonC $(2.05 \$ /$ tonC, $14.11 \$ /$ tonC $)$ respectively. It is worth noting the disparity between the implied SCC among countries that is suggested from the different discount rates applied. Indicatively, the implied SCC for the US is approximately three times the one for France and India.

Table 10 here

increases for a short period (moving up towards the mean) before starting its declining movement. 
Figure 2 graphically illustrates the evolution of benefits from abatement through time for each of the countries in the sample. For all countries in the sample except the US, contributions fall significantly after the $150^{\text {th }}$ year. For example, the marginal contributions are close to zero for South Africa, Japan, Germany and the UK after the $200^{\text {th }}$ year. Counter to this, the marginal benefits for the US remain noticeable until the $250^{\text {th }}$ year.

Figure 2 here

\subsection{Using the Baseline + Market Impact + Non-market Impact Damages Scenario of the Stern Review}

Our purpose is to compare the implications on the monetary valuation of the damages from climate change from the two different models (FUND 2.8 and PAGE2002) under different discounting regimes. In this section, we present the results implied from the baseline + market + non market damages from the Stern Review. The baseline scenario in the Stern Review is designed to be consistent with the Intergovernmental Panel on Climate Change (IPCC) third assessment report and assumes a mean warming of $3.9^{\circ} \mathrm{C}$ relative to pre-industrial levels by 2100 . The IPCC's third assessment report estimates a mean temperature increase ranging from $1.5^{\circ} \mathrm{C}$ to $4.5^{\circ} \mathrm{C}$.

The damages are estimated using the integrated assessment model employed by the Review that combines scientific models of climate change and economic modelling of the effects of climate change. As stated in the text the assumption of the Review is that climate change depresses the growth rate. According to the Stern Review, the primary sources of emissions in the future will be today's developing nations and China is expected to account for one third of the increase. The Review reports evidence that economic growth has lead 
to decarbonisation of the rich developed economies through changes in the production process, demand patterns and institutional changes. Nevertheless, it implies that we cannot rely on this effect for facing climate change and policies limiting $\mathrm{CO}_{2}$ emissions are required. Under a Business as Usual Scenario, $\mathrm{CO}_{2}$ emissions will continue to increase. According to the simulations in the Review the largest component of $\mathrm{CO}_{2}$ emissions will be a by-product of energy production. To break down $\mathrm{CO}_{2}$ emissions from energy production to its constituent parts the Review employs the Kave identity according to which:

$\mathrm{CO}_{2}$ emissions from energy $=$ Population $*$ GPD per Head*(Energy Use/GDP)*

$$
\text { ( } \mathrm{CO}_{2} \text { emissions/Energy Use) }
$$

Hence, an increase in global GDP is expected to increase emissions from energy unless there are offsetting effects from the emissions intensity of energy use or the energy intensity of GDP.

Damages from climate change as illustrated in the Stern Review are significantly different in their format compared to those reported from the FUND 2.8 model. Damages in the former are reported as monetary and percentage losses in per capita GDP relative to the per capita GDP in the state of the world under no climate change. Since the Review does not describe how the social cost of carbon is calculated and since it reports no series of projected emissions it is not possible to calculate the SCC in this case. However, we can derive the implications of the two discount factor weighting schemes to the overall damages from climate change reported by the Review, as well as the implications for the welfare of individual countries in the sample. 
In order to be consistent with the previous section and in line with the estimated discounting profiles we assume that all present values are reported as of 2005 for damages occurring from 2006 onwards. Contrary to the Stern Review, in the calculations, we assume that the horizon is 400 years instead of 200 years to account for the full length of the discounting profile. Since the damages are reported in intervals, we assume that for years within those intervals the decrease in GDP is equal to the damage for the interval. The damages between the $200^{\text {th }}$ and $400^{\text {th }}$ year are assumed to be equal to those of the $200^{\text {th }}$ year while damages after the $400^{\text {th }}$ year are ignored.

In Table 11 we report the present value of damages from climate change using different discounting profiles (that is GDP weighting, Population weighting, constant 1.4 percent, as well as GDP and Population weighting based on a 3.5 percent initial value). Damages from climate change are defined as the difference between the projected GDP per capita under no climate change and under the baseline scenario in the Stern Review. The results indicate that the present value of damages under the GDP weighting is approximately twice the present value of damages under population weighting. Specifically, over the 400 year horizon the average present value of damages per capita in the baseline scenario is $\$ 10505.61$ under GDP weighting while it is $\$ 5056.85$ under population weighting. Damages under the constant $1.4 \%$ regime greatly exceed the declining rate regimes with the resulting present value being $\$ 76099$. Given that the estimate specified by the Stern Review for the mean per capita income in 2001 is $\$ 7240$, the present value of the damages calculated for the GDP weighting, population weighting and the constant $1.4 \%$ profile are $1.45,0.69$ and 10.5 times the 2001 mean per capita income respectively. Using an initial rate of $3.5 \%$ in the simulation exercise to estimate the 
GDP and Population weighted discount profiles produces slightly higher damage estimates compared to the original ones: the PV is 10832.79 and 5382.90 respectively.

Table 11 here

To evaluate the dynamic evolution of damages, we calculate the aggregate present value of the difference between the no climate change scenario and the baseline scenario for each year, under all the discount profiles. The results are reported in Table 12. It is worth noting that for all discounting profiles, more than half of the value of per capita damages from climate change, arises during the time period between years 200 to 400 , which is not accounted for in the Stern Review. This effect is greater for the population-weighted discounting profile. Adopting a 200 year horizon suggests that the present value of damages for the GDP, the Population and the constant $1.4 \%$ profiles are $\$ 5559, \$ 3014$ and $\$ 29798$, respectively. Furthermore, when using a 3.5 percent as an initial value in the simulations, the relevant values for the GDP and Population weighted profiles are $\$ 5762$ and $\$ 3242$ respectively. The evolution of the present value of damages over time is also visualized in Figure 3. It is evident that the two alternative GDP-based discount profiles (i.e. one calculated using the sample mean as an initial value and one calculated using a 3.5 percent as an initial value) generate almost identical damages. The same holds for the two alternative population-based discount profiles.

Table 12 here

Figure 3 here

As illustrated in Tables 11, 12 and Figure 3, the choice of the discounting profile has significant impacts on the valuation of damages borne by climate change over the specified 400 year horizon. Adopting either of the two weighted declining discounting 
profiles, results to substantially lower estimates of climate change damages compared to the ones derived in the Stern Review. This is attributed, to a large extent, to the small value of the pure time discount rate that is assumed in the Review, in order to accommodate damages across generations in an egalitarian fashion. Nevertheless, a declining discount profile can correct the insufficient representation of future generations, but at the same time better maintain that current generations discount the future.

The analysis also reveals that the calculated valuations of climate change damages from the two alternative weighted discount profiles are of the same magnitude. However, we observe that the GDP-based DDR produces slightly higher valuation of climate change damages compared to the population-based DDR. This stems from the fact that the two weighting schemes (and as a result the corresponding DDRs) are not similar with respect to their ability to 'represent' the 'global situation'. In terms of GDP, our sample represents about 46.8 percent of the world's GDP. On the other hand, our sample represents only 28.34 percent of the world's population. As a result, the GDP-based DDR is clearly a better approximation to the 'global DDR'. We believe that the two aggregate DDRs would become similar to each other if it was feasible to include additional large countries in the analysis.

\section{CONCLUDING REMARKS}

Our main point in this paper is that when uncertainty is taken into account, the case for the use of Declining Discount Rates (DDRs) in long-run cost-benefit analyses becomes compelling. The decision to replace constant discount rates with DDRs has serious policy implications. In fact, such a decision implies that the policy maker will put relatively more 
effort to improve social welfare in the far distant future than in the shorter time. In this paper we emphasize that the relative value of this effort cannot be decided arbitrarily. A theory-consistent and empirically reliable estimation method is needed. To develop this method, we assume a declining, but time-stable structure of discount rates, and connect the representative-individual intergenerational theory with the empirical treatment of country-specific historical data. The application of our method gives empirical estimates of DDRs schedule. This estimated schedule is used for the calculation of a sequence of aggregate ('global') DDR schedule, which is used for the CBA of climate change mitigation policies. Our results add to the 'discount rate-related' criticism of the Stern Review, that is, the results of the Review are driven by an arbitrarily low constant discount rate. In conclusion, we claim that a DDR profile, if correctly estimated, can correct the insufficient representation of future generations, but at the same time better maintain that current generations discount the future.

One of the most important contributions of this paper is that it proposes how the theory consistent optimal long-run trajectory of the decline in discount rates can be efficiently estimated, without the use of a structural model. We believe that structural models are well-suited for short-term forecasts. However, their empirical implementation to describe the behaviour of the term structure of the interest rate in the distant future creates a number of problems, which we have discussed in section 3. Our alternative approach describes interest rates by means of a simple univariate time series model and is based on the assumption that the past behavior of interest rates can reveal useful information about the future dynamics of the series. Our model describes the uncertainty in the behavior of interest rates. This uncertainty together with persistence of the interest rates 
leads to DDRs. The utilization of a univariate model allows us to extend the estimation sample using long historical data that cover more than 200 years in some cases. This allows us to capture many historical events that affect the stochastic characteristics of the interest rate series for the nine 'representative' countries we study. In particular, we use regime-switching models to describe the stochastic dynamics of the real interest rate and derive a schedule of DDR for each country under scrutiny.

We then compose two alternative weighted declining discounting profiles that can be used in cost-benefit analyses of 'global' projects: the GDP-based DDR and the population-based DDR. These two profiles are applied on the cost-benefit evaluation of carbon mitigation policies and the conclusions of the Stern Report. We believe that this is a very timely exercise, given that much of the critique of the Review has focused on the low discount rate used in the analysis and how this drives the central results. Adopting either of the two weighted declining discounting profiles, results to substantially lower estimates of climate change damages compared to the ones derived in the Stern Review. This is attributed, to a large extent, to the small value of the pure time discount rate that is assumed in the Review, in order to accommodate damages across generations in an egalitarian fashion. Our declining discount profiles correct the insufficient representation of future generations, but at the same time better maintain that current generations discount the future. We should note however that the estimated confidence intervals for the valuation of carbon mitigation policies reveal the uncertainty that surrounds the calculated net present values of climate change damages in cases where the (unknown) future discount rates are very low or high. 
In closing this paper we want to briefly mention possible future research directions. Our methodology for the estimation of country-specific DDRs and the calculation of an aggregate DDR is based on univariate specifications for the interest rates. Thus, our empirical approach ignores the future stochastic consumption-growth process. The theoretical work of Gollier (2007) and Weitzman (2007b) provides a promising route for future investigation where consumption growth (and especially consumption growth-rate volatility) and people's preferences enter the analysis for the calculation of a DDR. 


\section{REFERENCES}

Ang, A. and G. Bekaert (2002). 'Regime Switches in Interest Rates', Journal of Business and Economic Statistics, 20, 163-182.

Arrow, K. J. (1995). 'Economic Growth, Carrying Capacity, and the Environment', Ecological Economics, 15(2), 91-95.

Bansal, R. and H. Zhou (2002). 'Term Structure of Interest Rates with Regime Shifts', The Journal of Finance, 57(5), 1997-2043.

Black, F., E. Derman and W. Toy (1990). 'A One-factor Model of Interest Rates and its Application to Treasury Bond Options', Financial Analysts Journal, 46(1), 33-39.

Black, F. and P. Karasinski (1991). 'Bond and Option Pricing when Short Rates are Lognormal', Financial Analysts Journal, 47(4), 52-59.

Chan, K.C., G.A. Karolyi, F.A. Longstaff and A.B. Sanders (1992). 'An empirical Comparison of Alternative Models of the Short-term Interest Rate', Journal of Finance, 47, $1209-1227$.

Cowell, F. and K. Gardiner (1999). 'Welfare Weights', Report to the UK Office of Fair Trading (available at www.oft.gov.uk/NR/rdonlyres/).

Cox, J.C., J.E. Ingersoll and S.A. Ross (1985). 'A Theory of the Term Structure of Interest Rates', Econometrica, 53, 385-407.

Dasgupta, P. (2006). 'Comments on the Stern Review's Economics of Climate Change', available from: http://www.econ.cam.ac.uk/faculty/dasgupta/STERN.pdf 
Evans, D. and H. Sezer (2002). 'A Time Preference Measure of the Social Discount Rate for the UK', Applied Economics, 34, 1925-34.

Gollier, C. (2002a). 'Time Horizon and the Discount Rate', Journal of Economic Theory, 107(2), 463-73.

Gollier, C. (2002b). 'Discounting an Uncertain Future', Journal of Public Economics, 85, 149-166.

Gollier, C. (2007). 'The Consumption-Based Determinants of the Term Structure of Discount Rates', Mathematics and Financial Economics, forthcoming.

Gray, F.S. (1996). 'Modelling the Conditional Distribution of Interest Rates as a Regime-switching Process', Journal of Financial Economics, 42, 27-62.

Groom, B., P. Koundouri, E. Panopoulou and T. Pantelidis (2007). 'An Econometric Approach to Estimating Long-Run Discount Rates', Journal of Applied Econometrics, 22, 641-656.

Hamilton, J.D. (1988). 'Rational Expectations Econometric Analysis of Changes in Regime: An Investigation of the Term Structure of Interest Rates', Journal of Economic Dynamics and Control, 12, 385-423.

Hamilton, J.D. (1989). 'A New Approach to the Economic Analysis of Nonstationary Time Series and the Business Cycle', Econometrica, 57, 357-384. 
Hepburn, C., P. Koundouri, E. Panopoulou and T. Pantelidis (2008). 'Social Discounting under Uncertainty: A Cross-country Comparison', Journal of Environmental Economics and Management, forthcoming.

Ho, T.S.Y. and S.B. Lee (1986). 'Term Structure Movements and Pricing Interest Rate Contingent Claims', Journal of Finance, 41, 1011-1029.

Hull, J. and A. White (1990). 'Pricing Interest Rate Derivative Securities', Review of Financial Studies, 3(4), 573-592.

Newell, R. and W. Pizer (2003). 'Discounting the Benefits of Climate Change Mitigation: How Much Do Uncertain Rates Increase Valuations?', Journal of Environmental Economics and Management, 46 (1), 52-71.

Nordhaus, W. D. (2007). 'A Review of the Stern Review on the Economics of Climate Change', Journal of Economic Literature, 45(3), 686-702.

Pearce, D.W. and D. Ulph (1999). 'A Social Discount rate for the United Kingdom', in Pearce, D.W., Environmental Economics: Essays in Ecological Economics and Sustainable Development. Cheltenham: Edward Elgar, 268-285

Population Division of the Department of Economic and Social Affairs of the United Nations Secretariat (2005). World Population Prospects: The 2004 Revision. Highlights. New York: United Nations.

Ramsey, F.P. (1928). 'A Mathematical Theory of Saving', Economic Journal, 38, $543-59$. 
Sen, A.K. (1982). 'Approaches to the Choice of Discount Rate for Social Benefit-Cost Analysis', in Lind, R.C. (ed) Discounting for Time and Risk in Energy Policy. Washington, DC: Resources for the Future, 325-353.

Spackman, M. (1991). 'Discount Rates and Rates of Return in the Public Sector: Economic Issues', GB HM Treasury.

Stern, N. (1977). 'The Marginal Valuation of Income', in Artis, M. and R. Nobay (eds.), Studies in Modern Economic Analysis, Oxford: Blackwell.

Stern, N.H. (2006). 'The Economics of Climate Change', available at: http://www.hm-treasury.gov.uk/independent_reviews/stern_review_economics_climate_ change/stern_review_report.cfm

Strotz, R. (1956). 'Myopia and Inconsistency in Dynamic Utility Maximisation', Review of Economic Studies, 23, 165-180.

Tol, R.S.J. (2002a). 'Estimates of the Damage Costs of Climate Change. Part 1: Benchmark Estimates', Environmental \& Resource Economics, 21(1), 47-73.

Tol, R.S.J. (2002b). 'Estimates of the Damage Costs of Climate Change, Part II. Dynamic Estimates', Environmental \& Resource Economics, 21(2), 135-160.

Vasicek, O. (1977). 'An Equilibrium Characterisation of the Term Structure', Journal of Financial Economics, 5, 177-188.

Weitzman, M. (1998). 'Why the Far Distant Future Should be Discounted at its Lowest Possible Rate', Journal of Environmental Economics and Management, 36, 201-208. 
Weitzman, M. (1999). 'Just keep on discounting, but .... ', in Portney, P. and J. Weyant (eds.), Discounting and Intergenerational Equity, Washington DC, Resources for the Future, 23-30.

Weitzman, M.L. (2007a). 'A Review of the Stern Review on the Economics of Climate Change', Journal of Economic Literature, 45(3), 703-724.

Weitzman, M.L. (2007b). 'Subjective Expectations and Asset-Return Puzzles', American Economic Review, 97(4), 1102-1130.

Yohe, G. (2006). 'Some Thoughts on the Damage Estimates Presented in the Stern Review-An Editorial', The Integrated Assessment Journal, 6(3), 65-72. 


\section{APPENDIX A: Estimations and Model Selection}

We first estimate an Autoregressive model of order $\mathrm{p}(\mathrm{AR}(\mathrm{p}))$ for each series under examination. Specifically, the estimated model is:

$$
r_{t}=\eta+e_{t}, \quad e_{t}=\sum_{i=1}^{p} a_{i} e_{t-i}+\xi_{t}
$$

where $\xi_{t} \sim N\left(0, \sigma^{2}\right)$. The estimation results are reported in Table T1. Throughout this study, the lag order selection is based on the Hannan-Quinn Information criterion. ${ }^{13}$ The constant parameter AR model given in (A1) is probably unable to describe the dynamics of the interest rate series over a long period, since the existence of various economic crises alters the behavior of the interest rates. A simple estimation of the autoregressive parameters of the AR model for each country based on a rolling estimation sample of 60 observations, not reported for brevity, reveal that the estimated parameters are not constant over time. This is a clear indication that the estimates of the AR models are not reliable.

Table T1:

Estimated AR Models

\begin{tabular}{ccccc}
\hline \hline & France & India & Japan & S. Africa \\
\hline$\eta$ & 1.393 & 1.432 & 1.298 & 1.273 \\
& $(0.199)$ & $(0.295)$ & $(0.291)$ & $(0.223)$ \\
$\alpha_{1}$ & 1.217 & 1.353 & 0.898 & 1.103 \\
& $(0.022)$ & $(0.038)$ & $(0.044)$ & $(0.044)$ \\
$\alpha_{2}$ & --- & -0.483 & --- & -0.259 \\
& -0.440 & $(0.051)$ & & $(0.051)$ \\
$\alpha_{3}$ & $(0.033)$ & --- & --- & --- \\
& & -0.178 & & \\
$\alpha_{4}$ & --- & $(0.048)$ & --- & - \\
& 0.171 & 0.257 & --- & --- \\
$\alpha_{5}$ & $(0.023)$ & $(0.040)$ & 0.054 & 0.041 \\
$\sigma^{2}$ & 0.019 & 0.014 & $(0.003)$ & $(0.002)$ \\
\hline \hline
\end{tabular}

Notes: Standard errors are reported in the parentheses.

\footnotetext{
${ }^{13}$ In almost all cases, the Akaike and Schwartz Information Criteria select the same model.
} 
In the literature, there are various efforts to produce time-dependent models for the interest rate, i.e. models with time-varying parameters. ${ }^{14}$ Since the seminal works of Hamilton (1988, 1989), regime-switching (RS) models became a very popular class of models to describe the time-variation in the dynamics of interest rates. In this study, we consider the following two-regime model:

$$
r_{t}=\eta_{k}+e_{t}, \quad e_{t}=\sum_{i=1}^{p} a_{i}^{k} e_{t-i}+\xi_{t}
$$

where $\xi_{t} \sim N\left(0, \sigma_{k}^{2}\right), k=1,2$ for the first and second regime respectively. We allow the two regimes to have different lag order. This model allows the interest rate to have different behavior in different periods by moving from one regime to the other. In regards to the probability law governing the transition from the first regime to the second regime and vice versa, we assume the simplest case of a Markov 1 chain, that is

$$
\operatorname{Pr}\left(s_{t}=j \mid s_{t-1}=i, s_{t-2}=g, \ldots, r_{t-1}, r_{t-2}, \ldots\right)=\operatorname{Pr}\left(s_{t}=j \mid s_{t-1}=i\right)=p_{i j}
$$

where $i, j=1,2$. In other words, the probability of being in regime $\mathrm{j}$ at time $\mathrm{t}\left(s_{t}=j\right)$ depends on only the most recent regime $\left(s_{t-1}\right)$.

The estimation results, reported in Table $\mathrm{T} 2$, show that the first regime corresponds to periods of low real interest rates and high volatility, while the second regime corresponds to periods of high real interest rates and low volatility. In all cases both regimes are persistent as indicated by the estimated transition probabilities which are always above 90 percent. In other words, the estimation results suggest that we do not observe many regime switches during the period under scrutiny. This is illustrated in

\footnotetext{
${ }^{14}$ See, inter alia, Ho and Lee (1986), Black et al. (1990), Hull and White (1990) and Black and Karasinski (1991).
} 
Figure F1 that presents the ex-post smoothed probability of being in the first regime, i.e. $p_{1, t}=\operatorname{Pr}\left(s_{t}=1 \mid \Omega_{t}\right)$ where $\Omega_{t}$ is the information set available at time $t$, for each one of the estimated models.

Table T2:

Estimated Regime-Switching Models

\begin{tabular}{|c|c|c|c|c|}
\hline & France & India & Japan & S. Africa \\
\hline & \multicolumn{4}{|c|}{ Regime 1} \\
\hline$\eta_{1}$ & $\begin{array}{c}1.179 \\
(0.411)\end{array}$ & $\begin{array}{c}1.091 \\
(0.225)\end{array}$ & $\begin{array}{c}0.989 \\
(0.244)\end{array}$ & $\begin{array}{c}1.194 \\
(0.282)\end{array}$ \\
\hline$\alpha_{1}^{1}$ & $\begin{array}{c}1.300 \\
(0.105)\end{array}$ & $\begin{array}{c}1.219 \\
(0.172)\end{array}$ & $\begin{array}{c}0.563 \\
(0.135)\end{array}$ & $\begin{array}{c}0.754 \\
(0.044)\end{array}$ \\
\hline$\alpha_{2}{ }^{1}$ & $\begin{array}{c}-0.393 \\
(0.131)\end{array}$ & $\begin{array}{l}-0.486 \\
(0.177)\end{array}$ & $\begin{array}{c}0.478 \\
(0.193)\end{array}$ & --- \\
\hline$\alpha_{3}{ }^{1}$ & --- & --- & --- & --- \\
\hline$\alpha_{4}{ }^{1}$ & --- & --- & $\begin{array}{l}-0.311 \\
(0.148)\end{array}$ & --- \\
\hline$\alpha_{5}{ }^{1}$ & --- & --- & --- & --- \\
\hline \multirow[t]{2}{*}{$\sigma_{1}^{2}$} & $\begin{array}{c}0.072 \\
(0.008)\end{array}$ & $\begin{array}{c}0.064 \\
(0.012)\end{array}$ & $\begin{array}{c}0.110 \\
(0.024)\end{array}$ & $\begin{array}{c}0.098 \\
(0.012)\end{array}$ \\
\hline & \multicolumn{4}{|c|}{ Regime 2} \\
\hline$\eta_{2}$ & $\begin{array}{c}1.484 \\
(0.168)\end{array}$ & $\begin{array}{l}1.565 \\
(0.174)\end{array}$ & $\begin{array}{c}1.133 \\
(0.490)\end{array}$ & $\begin{array}{c}1.395 \\
(0.049)\end{array}$ \\
\hline$\alpha_{1}^{2}$ & $\begin{array}{c}1.623 \\
(0.053)\end{array}$ & $\begin{array}{l}1.729 \\
(0.039)\end{array}$ & $\begin{array}{c}1.392 \\
(0.039)\end{array}$ & $\begin{array}{l}1.781 \\
(0.045)\end{array}$ \\
\hline$\alpha_{2}^{2}$ & $\begin{array}{c}-0.378 \\
(0.106)\end{array}$ & $\begin{array}{l}-0.741 \\
(0.039)\end{array}$ & $\begin{array}{l}-0.367 \\
(0.050)\end{array}$ & $\begin{array}{l}-0.834 \\
(0.045)\end{array}$ \\
\hline$\alpha_{3}^{2}$ & $\begin{array}{l}-0.439 \\
(0.080)\end{array}$ & --- & --- & -- \\
\hline$\alpha_{4}^{2}$ & --- & --- & $\begin{array}{l}-0.147 \\
(0.066)\end{array}$ & --- \\
\hline$\alpha_{5}^{2}$ & $\begin{array}{c}0.178 \\
(0.028)\end{array}$ & --- & $\begin{array}{c}0.110 \\
(0.035)\end{array}$ & --- \\
\hline \multirow[t]{2}{*}{$\sigma_{2}^{2}$} & $\begin{array}{c}0.001 \\
(0.000)\end{array}$ & $\begin{array}{c}0.001 \\
(0.000)\end{array}$ & $\begin{array}{l}0.0004 \\
(0.000)\end{array}$ & $\begin{array}{l}0.0005 \\
(0.000)\end{array}$ \\
\hline & \multicolumn{4}{|c|}{ Transition Probabilities } \\
\hline $\mathrm{p}_{11}$ & $\begin{array}{c}0.942 \\
(0.029)\end{array}$ & $\begin{array}{c}0.947 \\
(0.047)\end{array}$ & $\begin{array}{c}0.924 \\
(0.040)\end{array}$ & $\begin{array}{c}0.978 \\
(0.018)\end{array}$ \\
\hline $\mathrm{p}_{22}$ & $\begin{array}{c}0.974 \\
(0.013)\end{array}$ & $\begin{array}{c}0.981 \\
(0.012)\end{array}$ & $\begin{array}{c}0.949 \\
(0.028)\end{array}$ & $\begin{array}{c}0.976 \\
(0.020)\end{array}$ \\
\hline
\end{tabular}

Notes: Standard errors are reported in the parentheses. 
Figure F1:

Smoothed Probability of the First Regime
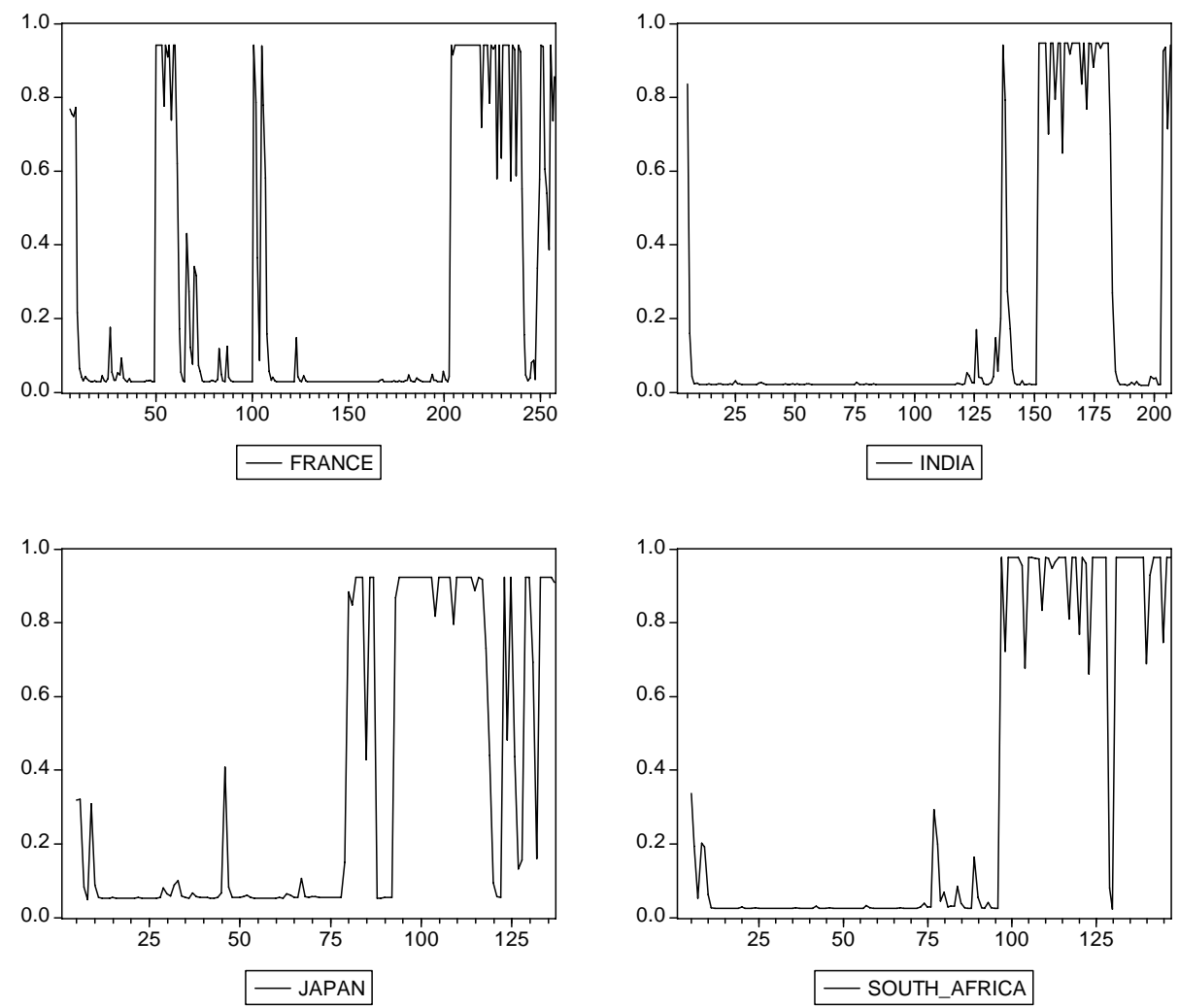

The rolling estimation of the simple AR models showed that the AR parameters are unstable revealing a time-variation in the dynamics of the real interest rates. We tried to capture this time-dependence of the series under examination by estimating a regime-switching model. An informal way to evaluate whether RS is an adequate representation of the data is to calculate the Regime Classification Measure (RCM) proposed by Ang and Bekaert (2002). In the case of a model with two regimes, RCM is based on $p_{1, t}$. Specifically,

$$
R C M=400 * \frac{1}{T} \sum_{t=1}^{T} p_{1, t}\left(1-p_{1, t}\right)
$$

where $\mathrm{T}$ is the sample size. By construction, RCM ranges between 0 and 100 . The idea behind RCM is that the regime-switching model is good if we are able to classify regimes 
sharply. In the extreme case where we are certain about the regime, i.e. $p_{1, t}=0$ or 1 for every $\mathrm{t}, \mathrm{RCM}$ equals zero. In the other extreme case where $p_{1, t}=0.5$ for every $\mathrm{t}, \mathrm{RCM}$ equals 100 . To sum up, the closer RCM is to zero, the stronger is the evidence in favor of RS. The computed values of RCM for each interest rate, reported in Panel A of Table T3, range from 15.638 (India) to 31.101 (Japan), suggesting that RS is a rather good model for our data.

Table T3:

Model Evaluation Criteria

\begin{tabular}{ccccc}
\hline \hline & \multicolumn{4}{c}{ Panel A: RCM } \\
& France & India & Japan & S. Africa \\
\hline RCM & 24.324 & 15.638 & 31.101 & 17.415 \\
& \multicolumn{5}{c}{ Panel B: In-Sample Forecast Exercise } \\
\hline MSFE(AR) & 0.302 & 0.284 & 0.255 & 0.258 \\
MSFE(RS) & 0.238 & 0.219 & 0.214 & 0.254 \\
Ratio & 0.789 & 0.770 & 0.841 & 0.986 \\
\hline \hline Notes: & Ratio $=[$ MSFE(RS) $/$ MSFE(AR) $]$ &
\end{tabular}

However, as already mentioned, RCM is not a formal procedure to test the adequacy of RS. We now compare AR and RS in the context of an in-sample forecast exercise. ${ }^{15}$ More specifically, we use the estimated AR and RS models to generate forecasts for the last 100 observations of our sample. We then calculate the Mean Square Forecast Error (MSFE) for both models. For each country, we also compute the ratio of the MSFE of RS over the MSFE of AR. If this ratio is lower than unity, RS outperforms AR. The results, presented in Panel B of Table T3, highlight the superiority of RS over AR. In

\footnotetext{
${ }^{15}$ Unfortunately, we cannot choose between the single-regime AR model and the two-regime RS model by means of standard likelihood ratio, Lagrange multiplier and Wald tests because of the existence of nuisance parameters which are not identified under the null hypothesis. For this reason, empirical studies choose among such models based on simple criteria such as a forecast exercise.
} 
general, the results show strong evidence in favor of RS. The only exception is South Africa where the superiority of RS is marginal.

In summary, the picture emerging from (i) the rolling estimation of AR models, (ii) RCM and (iii) the in-sample forecast exercise, support the utilization of RS to describe the real interest rates under consideration. 
Table 1:

Data Information

\begin{tabular}{ccccc}
\hline \hline & & Nominal Interest Rates & & \\
\cline { 3 - 4 } Country & Bond & Period & Source & Code \\
\hline France & 10Y Government Bond Yield & $1746-2006$ & Global Financial Data & IGFRA10D \\
India & Government Bond Yield & $1800-2006$ & $-/ /-$ & IGIND10D \\
Japan & 7Y Government Bond Yield & $1870-2006$ & $-/ /-$ & IGJPN7D \\
S. Africa & 20Y Government Bond Yield & $1860-2006$ & $-/ /-$ & IGZAF20D \\
\cline { 1 - 4 } Country & & CPI \% Change & \\
France & $1950-2006$ & Source & Code \\
India & $1950-2006$ & IFS & ifs:s1326400xzfa \\
Japan & $1950-2006$ & $-/ /-$ & ifs:s5346400xzfa \\
S. Africa & $1955-2006$ & $-/ /-$ & ifs:s1586400xzfa \\
\hline
\end{tabular}

Table 2:

Descriptive Statistics

\begin{tabular}{ccccc}
\hline \hline & France & India & Japan & S. Africa \\
\hline Mean & 1.444 & 1.428 & 1.423 & 1.278 \\
Median & 1.456 & 1.410 & 1.561 & 1.368 \\
Maximum & 3.132 & 2.420 & 2.135 & 2.051 \\
Minimum & -0.698 & -0.183 & -0.042 & -1.435 \\
St. Deviation & 0.486 & 0.393 & 0.495 & 0.435 \\
Skewness & -0.590 & -0.434 & -1.293 & -3.232 \\
Kurtosis & 6.764 & 6.115 & 4.054 & 18.160 \\
\hline \hline
\end{tabular}


Table 3:

Certainty-Equivalent Discount Factors

\begin{tabular}{c|cccc|ccccc}
\hline \hline & France & India & Japan & S. Africa & Australia & Canada & Germany & UK & US \\
\hline $\mathbf{1}$ & 0.95398 & 0.95708 & 0.95728 & 0.96255 & 0.96518 & 0.96297 & 0.96139 & 0.96524 & 0.95965 \\
$\mathbf{2 0}$ & 0.40911 & 0.42766 & 0.46101 & 0.46765 & 0.52072 & 0.50613 & 0.46873 & 0.50136 & 0.57180 \\
$\mathbf{4 0}$ & 0.17939 & 0.18524 & 0.22272 & 0.22208 & 0.28365 & 0.27544 & 0.23058 & 0.25369 & 0.34967 \\
$\mathbf{6 0}$ & 0.08214 & 0.08241 & 0.11176 & 0.10697 & 0.15663 & 0.15454 & 0.11630 & 0.12910 & 0.22350 \\
$\mathbf{8 0}$ & 0.03899 & 0.03760 & 0.05799 & 0.05224 & 0.08731 & 0.08881 & 0.05975 & 0.06615 & 0.14756 \\
$\mathbf{1 0 0}$ & 0.01908 & 0.01756 & 0.03093 & 0.02590 & 0.04900 & 0.05200 & 0.03123 & 0.03410 & 0.09959 \\
$\mathbf{1 5 0}$ & 0.00365 & 0.00290 & 0.00712 & 0.00479 & 0.01189 & 0.01472 & 0.00666 & 0.00668 & 0.03956 \\
$\mathbf{2 0 0}$ & 0.00085 & 0.00057 & 0.00185 & 0.00097 & 0.00302 & 0.00458 & 0.00160 & 0.00137 & 0.01654 \\
$\mathbf{2 5 0}$ & 0.00025 & 0.00014 & 0.00054 & 0.00022 & 0.00081 & 0.00155 & 0.00045 & 0.00030 & 0.00711 \\
$\mathbf{3 0 0}$ & 0.00010 & 0.00005 & 0.00018 & 0.00005 & 0.00023 & 0.00056 & 0.00016 & 0.00007 & 0.00311 \\
$\mathbf{3 5 0}$ & 0.00005 & 0.00002 & 0.00007 & 0.00001 & 0.00008 & 0.00022 & 0.00007 & 0.00002 & 0.00138 \\
$\mathbf{4 0 0}$ & 0.00003 & 0.00001 & 0.00003 & 0.00000 & 0.00003 & 0.00009 & 0.00004 & 0.00001 & 0.00061 \\
\hline \hline
\end{tabular}

Table 4:

Certainty-Equivalent Discount Rates

\begin{tabular}{|c|c|c|c|c|c|c|c|c|c|}
\hline & France & India & Japan & S. Africa & Australia & Canada & "Germany & 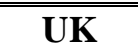 & $\overline{\text { US }}$ \\
\hline 1 & 0.04824 & 0.04484 & 0.04463 & 0.03891 & 0.03608 & 0.03845 & 0.04016 & 0.03601 & 0.04205 \\
\hline 20 & 0.04357 & 0.04342 & 0.03821 & 0.03836 & 0.03145 & 0.03203 & 0.03705 & 0.03486 & 0.02621 \\
\hline 40 & 0.04091 & 0.04204 & 0.03608 & 0.03758 & 0.03045 & 0.03015 & 0.03539 & 0.03455 & 0.02373 \\
\hline 60 & 0.03891 & 0.04069 & 0.03421 & 0.03690 & 0.02987 & 0.02865 & 0.03430 & 0.03420 & 0.02174 \\
\hline 80 & 0.03719 & 0.03946 & 0.03263 & 0.03606 & 0.02949 & 0.02763 & 0.03346 & 0.03385 & 0.02037 \\
\hline 100 & 0.03568 & 0.03826 & 0.03128 & 0.03530 & 0.02914 & 0.02669 & 0.03255 & 0.03353 & 0.01944 \\
\hline 150 & 0.03188 & 0.03510 & 0.02856 & 0.03340 & 0.02829 & 0.02460 & 0.03020 & 0.03272 & 0.01801 \\
\hline 200 & 0.02704 & 0.03114 & 0.02614 & 0.03133 & 0.02728 & 0.02279 & 0.02761 & 0.03166 & 0.01727 \\
\hline 250 & 0.02188 & 0.02542 & 0.02366 & 0.02921 & 0.02601 & 0.02114 & 0.02414 & 0.03011 & 0.01684 \\
\hline 300 & 0.01657 & 0.01822 & 0.02063 & 0.02718 & 0.02407 & 0.01965 & 0.01894 & 0.02689 & 0.01655 \\
\hline 350 & 0.01154 & 0.01098 & 0.01749 & 0.02539 & 0.02078 & 0.01812 & 0.01330 & 0.02157 & 0.01634 \\
\hline 400 & 0.01064 & 0.00858 & 0.01390 & 0.02358 & 0.01654 & 0.01650 & 0.00864 & 0.01262 & 0.01620 \\
\hline
\end{tabular}


Table 5:

Weights Used in Aggregation

\begin{tabular}{clc}
\hline \hline & GDP $^{(\mathbf{i})}$ & Population in 2005 $^{(\mathbf{i i})}$ \\
\hline Australia & 0.0225 & 0.0110 \\
Canada & 0.0375 & 0.0176 \\
France & 0.0644 & 0.0330 \\
Germany & 0.0846 & 0.0451 \\
India & 0.1316 & 0.6022 \\
Japan & 0.1391 & 0.0699 \\
South Africa & 0.0181 & 0.0259 \\
UK & 0.0697 & 0.0326 \\
US & 0.4324 & 0.1627 \\
\hline
\end{tabular}

Notes: (i) GDP is gross domestic product converted to international dollars using purchasing power parity rates. An international dollar has the same purchasing power over GDP as the US dollar has in the US. Data are in constant 2000 international dollars. Source: The World Bank Group (Ecowin)

(ii) Source: Population Division of the Department of Economic and Social Affairs of the United Nations Secretariat (2005). World Population Prospects: The 2004 Revision. Highlights. New York: United Nations.

Table 6:

Weighted Average Certainty-Equivalent Discount Rates

\begin{tabular}{c:cc}
\hline \hline & $\begin{array}{c}\text { GDP } \\
\text { weighted }\end{array}$ & $\begin{array}{c}\text { Population } \\
\text { 2005 weighted }\end{array}$ \\
\hline $\mathbf{1}$ & 0.04226 & 0.04362 \\
$\mathbf{2 0}$ & 0.03252 & 0.03848 \\
$\mathbf{4 0}$ & 0.02957 & 0.03578 \\
$\mathbf{6 0}$ & 0.02694 & 0.03302 \\
$\mathbf{8 0}$ & 0.02479 & 0.03040 \\
$\mathbf{1 0 0}$ & 0.02305 & 0.02795 \\
$\mathbf{1 5 0}$ & 0.02003 & 0.02295 \\
$\mathbf{2 0 0}$ & 0.01833 & 0.01979 \\
$\mathbf{2 5 0}$ & 0.01737 & 0.01799 \\
$\mathbf{3 0 0}$ & 0.01677 & 0.01691 \\
$\mathbf{3 5 0}$ & 0.01633 & 0.01607 \\
$\mathbf{4 0 0}$ & 0.01598 & 0.01543 \\
\hline \hline
\end{tabular}

Table 7:

Social Cost of Carbon

\begin{tabular}{|c|c|c|c|}
\hline Discount Regime & Average & $\begin{array}{c}\text { Lower bound } \\
(2.5 \%)\end{array}$ & $\begin{array}{c}\text { Upper bound } \\
(97.5 \%)\end{array}$ \\
\hline $\begin{array}{c}\text { GDP weighted } \\
\text { Population } 2005 \text { weighted } \\
\text { Stern Review (constant 1.4\%) }\end{array}$ & $\begin{array}{l}\$ 12.60 / \text { tonC } \\
\$ 8.85 / \text { tonC } \\
\$ 40.15 / \text { tonC }\end{array}$ & $\begin{array}{c}\text { Panel A } \\
\$ 3.09 / \text { tonC } \\
\$ 2.48 / \text { tonC }\end{array}$ & $\begin{array}{l}\$ 23.69 / \text { tonC } \\
\$ 17.99 / \text { tonC }\end{array}$ \\
\hline $\begin{array}{c}\text { GDP weighted }(3.5 \%) \\
\text { Population } 2005 \text { weighted } \\
(3.5 \%)\end{array}$ & $\begin{array}{l}\text { 13.18/tonC } \\
9.67 / \text { tonC }\end{array}$ & $\begin{array}{c}\text { Panel B } \\
--- \\
---\end{array}$ & $\begin{array}{l}--- \\
---\end{array}$ \\
\hline
\end{tabular}


Table 8:

Present Value of benefits per ton of $\mathrm{CO}_{2}$ at selected years.

\begin{tabular}{cccccc}
\hline \hline Year & GDP weighted & $\begin{array}{c}\text { Population } \\
\text { 2005 weighted }\end{array}$ & $\begin{array}{c}\text { Stern Review } \\
\text { (constant 1.4\%) }\end{array}$ & $\begin{array}{c}\text { GDP weighted } \\
(3.5 \%)\end{array}$ & $\begin{array}{c}\text { Population } \\
\text { 2005 weighted } \\
(3.5 \%)\end{array}$ \\
\hline 10 & 0.07422 & 0.074223 & 0.095722 & 0.079695 & 0.077970 \\
40 & 3.42391 & 2.978002 & 5.826381 & 3.578289 & 3.232165 \\
60 & 6.259189 & 5.127508 & 12.656796 & 6.559251 & 5.602161 \\
80 & 8.473170 & 6.622015 & 19.500945 & 8.883658 & 7.249224 \\
100 & 10.00701 & 7.551510 & 25.347640 & 10.488589 & 8.268427 \\
150 & 11.81427 & 8.507057 & 34.297050 & 12.368275 & 9.304159 \\
200 & 12.35556 & 8.752757 & 37.941475 & 12.926665 & 9.565557 \\
250 & 12.52064 & 8.821988 & 39.326951 & 13.096078 & 9.638309 \\
300 & 12.57384 & 8.843542 & 39.856331 & 13.150517 & 9.660812 \\
350 & 12.59195 & 8.850818 & 40.063549 & 13.169037 & 9.668394 \\
400 & 12.59855 & 8.853500 & 40.148489 & 13.175797 & 9.671199 \\
\hline \hline
\end{tabular}

Table 9:

Marginal Benefit from $\mathrm{CO}_{2}$ abatement per discounting pattern per year

\begin{tabular}{cccccc}
\hline \hline Year & GDP weighted & $\begin{array}{c}\text { Population } \\
\text { 2005 weighted }\end{array}$ & $\begin{array}{c}\text { Stern Review } \\
\text { (constant 1.4\%) }\end{array}$ & $\begin{array}{c}\text { GDP weighted } \\
(3.5 \%)\end{array}$ & $\begin{array}{c}\text { Population } \\
\text { 2005 weighted } \\
(3.5 \%)\end{array}$ \\
\hline 10 & 0.077404 & 0.074223 & 0.095722 & 0.079695 & 0.077970 \\
40 & 0.168391 & 0.135621 & 0.349793 & 0.176936 & 0.149159 \\
60 & 0.136245 & 0.097340 & 0.373440 & 0.143215 & 0.107419 \\
80 & 0.096196 & 0.061330 & 0.332112 & 0.100839 & 0.067448 \\
100 & 0.061824 & 0.035586 & 0.258963 & 0.064561 & 0.038879 \\
150 & 0.018584 & 0.008853 & 0.111828 & 0.019227 & 0.009482 \\
200 & 0.005538 & 0.002378 & 0.042782 & 0.005693 & 0.002509 \\
250 & 0.001728 & 0.000707 & 0.016088 & 0.001770 & 0.000739 \\
300 & 0.000571 & 0.000229 & 0.006176 & 0.000584 & 0.000239 \\
350 & 0.000207 & 0.000084 & 0.002542 & 0.000212 & 0.000087 \\
400 & 0.000079 & 0.000032 & 0.001076 & 0.000081 & 0.000034 \\
\hline \hline
\end{tabular}

Table 10:

Social Cost of Carbon per County

\begin{tabular}{cccc}
\hline \hline Country & Average & $\begin{array}{c}\text { Lower bound } \\
(2.5 \%)\end{array}$ & $\begin{array}{c}\text { Upper bound } \\
(97.5 \%)\end{array}$ \\
\hline Australia & 11.47 & 4.92 & 20.96 \\
Canada & 11.65 & 1.08 & 30.23 \\
France & 6.35 & 1.35 & 16.18 \\
Germany & 8.64 & 1.88 & 19.89 \\
India & 6.36 & 2.05 & 14.11 \\
Japan & 8.45 & 2.69 & 17.39 \\
South Africa & 7.95 & 3.07 & 16.05 \\
UK & 9.41 & 4.43 & 16.54 \\
US & 18.39 & 3.90 & 31.55 \\
\hline \hline
\end{tabular}


Table 11:

PV of damages in mean GDP per capita for a 400 year horizon (in US\$ at year 2000)

\begin{tabular}{cccc}
\hline \hline Discount Regime & Average & $\begin{array}{c}\text { Lower bound } \\
(2.5 \%)\end{array}$ & $\begin{array}{c}\text { Upper bound } \\
(97.5 \%)\end{array}$ \\
\hline GDP weighted & $\$ 10505.61$ & $\begin{array}{c}\text { Panel A } \\
\$ 505.102\end{array}$ & $\$ 29543.11$ \\
Population 2005 weighted & $\$ 5056.85$ & $\$ 406.54$ & $\$ 15113.85$ \\
Stern Review (constant 1.4\%) & $\$ 76099.64$ & --- & - \\
GDP weighted (3.5\%) & $\$ 10832.79$ & Panel B & --- \\
Population 2005 weighted & $\$ 5382.90$ & --- & --- \\
$(3.5 \%)$ & & & \\
\hline \hline
\end{tabular}

Table 12:

PV of mean per capita damages under the baseline scenario by year (in year 2000 \$US)

\begin{tabular}{cccccc}
\hline \hline Year & GDP weighted & $\begin{array}{c}\text { Population } \\
\text { 2005 weighted }\end{array}$ & $\begin{array}{c}\text { Stern Review } \\
\text { (constant 1.4\%) }\end{array}$ & $\begin{array}{c}\text { GDP weighted } \\
(3.5 \%)\end{array}$ & $\begin{array}{c}\text { Population } \\
\text { 2005 weighted } \\
(3.5 \%)\end{array}$ \\
\hline 1 & 14.277 & 14.259 & 14.675 & 14.371 & 14.372 \\
10 & 136.697 & 134.039 & 154.617 & 139.419 & 138.152 \\
40 & 444.468 & 404.961 & 661.021 & 460.624 & 431.261 \\
60 & 675.435 & 578.727 & 1227.453 & 703.455 & 622.879 \\
80 & 997.007 & 793.599 & 2242.349 & 1040.976 & 859.605 \\
100 & 1489.678 & 1089.069 & 4157.770 & 1556.273 & 1183.360 \\
150 & 2929.434 & 1831.449 & 11662.309 & 3051.783 & 1985.852 \\
200 & 5559.091 & 3014.014 & 29798.564 & 5762.905 & 3242.259 \\
250 & 8493.470 & 4243.335 & 54528.639 & 8774.102 & 4533.843 \\
300 & 9729.871 & 4744.146 & 66868.996 & 10039.405 & 5056.683 \\
350 & 10267.058 & 4959.931 & 73026.858 & 10588.640 & 5281.551 \\
400 & 10505.612 & 5056.847 & 76099.643 & 10832.793 & 5382.897 \\
\hline \hline
\end{tabular}

Figure 1:

Evolution of Benefits from a Reduction of One Ton in $\mathrm{CO}_{2}$ Emissions

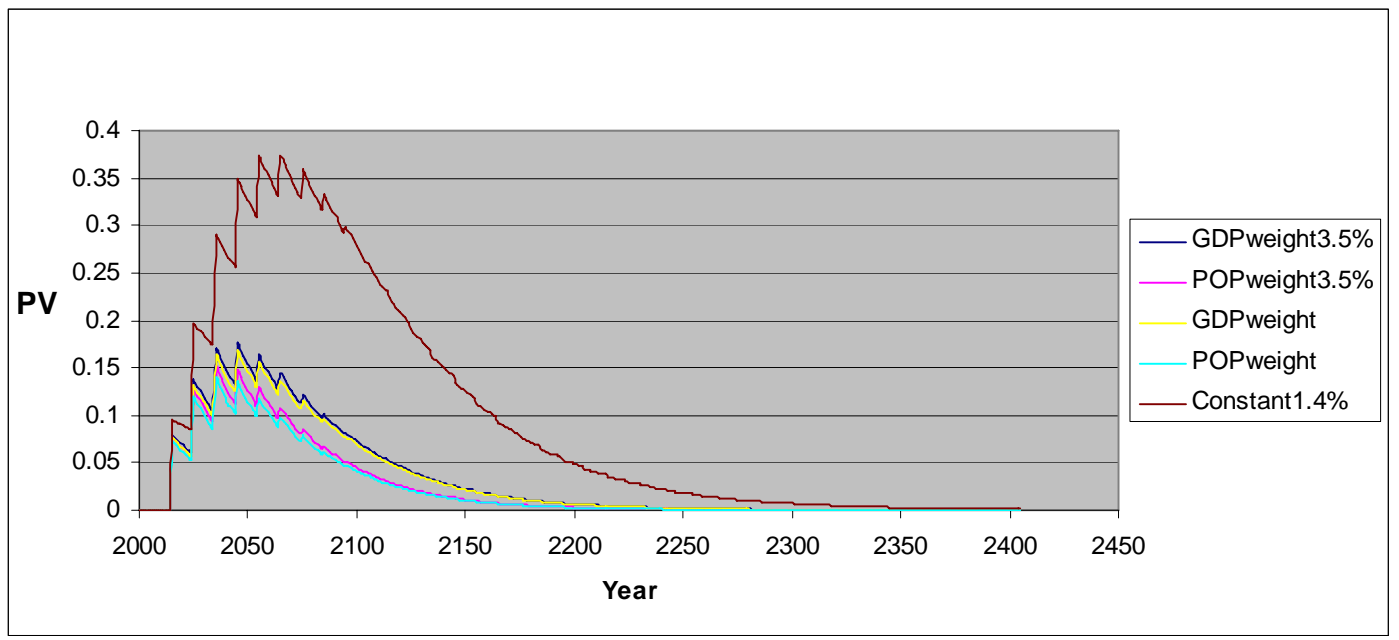


Figure 2:

Evolution of Benefits from a Reduction of One Ton in $\mathrm{CO}_{2}$ Emissions by Country

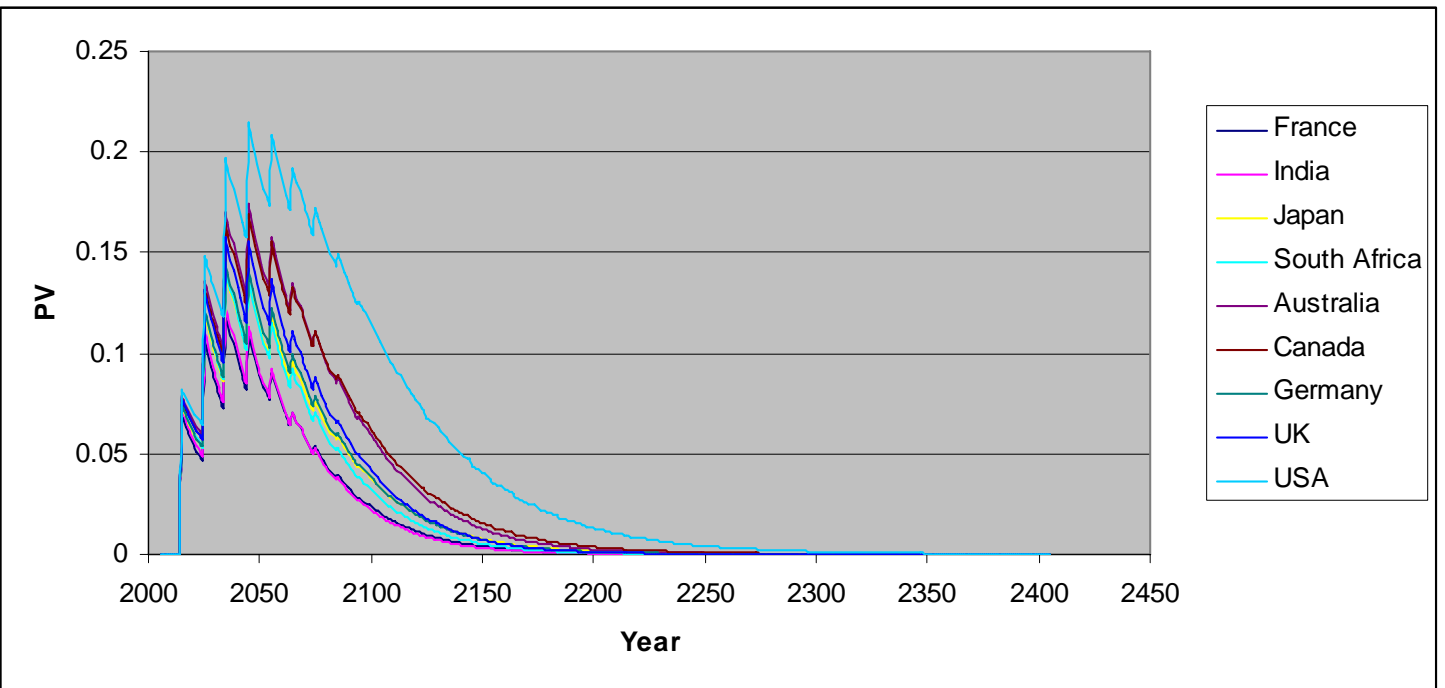

Figure 3:

Evolution of the Present Value of Damages

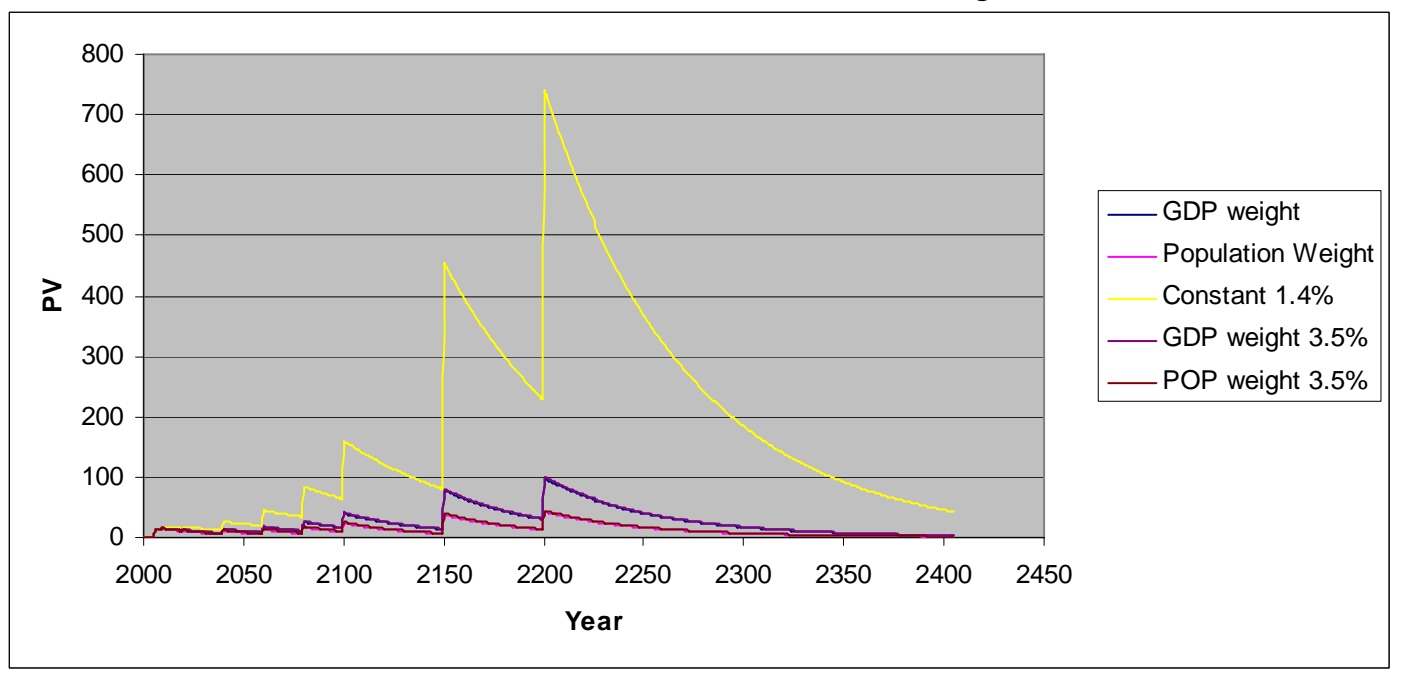

